\title{
Liquidity, Contagion and Financial Crisis ${ }^{1}$
}

\author{
Alexander Guembel \\ Oren Sussman \\ Toulouse School of Economics \\ Saïd Business School, \\ University of Oxford
}

November, 2009

\footnotetext{
${ }^{1}$ We would like to thank Jean-Charles Rochet Jean Tirole and seminar participants at SAET 2009 and Heriot Watt for helpful comments. This research benefited from the support of the research grant "Financial Markets and Investment Banking Value Chain" sponsored by the Fédération Bancaire Française. All remaining errors are ours.
} 


\begin{abstract}
In this paper we study the link between liquidity, firms' access to external finance, and the real economy. We show that there is a feedback mechanism from collateral requirements to the fire-sale price of capital goods. As a result, an "abnormality" appears whereby supply and demand for liquidity both slope in the same direction. This generates a "multiplier" that amplifies the effect of external shocks. Hence, a shock can become contagious and propel the economy into a financial crisis, whereby collateral is sold off below fundamental value and some companies become credit rationed. For intermediate levels of the shock, muliple equilibria appear where the government can costlessly implement policies to coordinate expectations away from dominated equilibria. For high levels of the shock, financial crisis is the unique equilibrium. The competitive-equilibrium probability of a financial crisis is strictly positive. Stabilization policies that inject liquidity or bailout companies may decrease the probability of a crisis and enhance welfare, but will have fiscal implications. We structure the model so that its key parameters have a simple corporate-finance interpretation. We use numerical examples to show that the model's quantitative fit is surprisingly good. Perhaps the most important implication of these numerical examples is that the ex-ante welfare effect of the stabilizing policies is very small.

Keywords: Debt deflation, bailout, liquidity injection

JEL Classifications:
\end{abstract}




\section{Introduction}

Writing back in 1873, Walter Bagehot made the observation that since "our credit system [is] much more delicate at some times than at others .. panics come according to a fixed rule, [so] that every ten years or so we must have one of them" ${ }^{1}$. The dramatic events of the last two years have forced us to reconsider some of the fundamental questions that preoccupied Bagehot and his contemporary financial economists: is a periodic crisis an inherent property of a competitive financial market? Is financial crisis a market failure? If so, what kind of policies should be implemented in order to diminish the social cost? Lastly, is neo-classical economics capable of providing a framework for the analysis of these questions?

There are three major approaches to the analysis of financial crisis. From McKay's (1841) "extraordinary popular delusions" to Shiller's (2000) "irrational exuberance" there is a view that financial crisis results from a black-out of human reason. We shall not consider this view here, if only because it is hard to square with a proper welfare analysis, which is one of our main objectives. Then, there is a view, initially formulated by Diamond and Dybvig (1983) and later elaborated by Morris and Shin (2004) and many others that crises result from a coordination failure, usually associated with a (defective) financial structure that has a built-in first-mover advantage, like demand deposits, or loss limits. Lastly, there is Fisher's (1933) debt-deflation theory that builds on "two dominant factors, namely over indebtedness to begin with and deflation following soon after" (emphasis in the original text). Fisher's own focus on the role of "distressed selling" and his statistical analysis hints that the main issue is not the nominal rigidity of debt contracts per se, but rather the drop (during crisis) in the relative price of capital goods and industrial output relative to the value of corporate debt, which drains away companies' equity. ${ }^{2}$

In the autumn of 1998, the US government managed, by sponsoring the rescue of LTCM, to stop the Asian-Russian financial crisis from spreading to the developed economies, with hardly any cost to tax-payers. That episode strengthened the view that financial crises may be a pure coordination fail-

\footnotetext{
${ }^{1}$ See Chapter V of Bagehot (1873), called "Why Lombard Street Is Often Very Dull, and Sometimes Extremely Excited".

${ }^{2}$ According to Fisher (see Chart V), from 1929 to 1933 the price level fell by 40\%, nominal debt by $20 \%$ while nominal national wealth fell by $59 \%$; so the price of capital goods must have fallen significantly more than $40 \%$.
} 
ure. Unfortunately, such an optimistic scenario failed to materialize during the current crisis. Governments have committed large amounts of resources with the intention of stabilizing the markets, but the effectiveness of the policy is still debated. This strongly suggests that coordination failures alone cannot provide a complete explanation of financial crises. Rather, Fisherian elements such as high levels of indebtedness, fire sales and depressed prices of capital goods seem to be important in understanding financial crisis. At the same time, it seems that multiple equilibria should play a role in a theory of financial crisis, perhaps for cases where the magnitude of the shock is relatively mild.

We believe that many of the theoretical building blocks that are necessary in order to construct a satisfactory theory of financial crisis have already been worked out. In this paper we attempt to move in the direction of an operational, macroeconomic model that integrates theories of liquidity provision - Alan and Gale (1998), Gorton and Huang (2004), Holmstrom and Tirole (1998) - with theories that explain how depressed capital-goods prices may adversely effect macroeconomic activity, as in Kiyotaki and Moore (1997). By "operational" we mean a model where the financial instruments are similar to the ones observed in reality, where most of the parameters can be identified by the financial statistics so that "realistic" numerical examples can provide some idea about the quantitative fit of the model. Equally important, the model's measure of social welfare can be related to standard national-accounting concepts such as Gross National Product (GNP).

We start the analysis by focusing our attention away from productivity shocks - for a long time the dominating view in the literature regarding the source of macroeconomic disturbances. Instead, we introduce shocks that redistribute capital across companies, and interpret them as pure financial shocks. In our model (unlike in the real world) there are no economically distressed companies, although some companies get into financial distress through a combination of high leverage and a temporary shortage of earnings. If the Modigliani-Miller Theorem were to apply in our model, the shock would have no macroeconomic implications. This, however, is not the case due to verifiability problems that generate financial frictions all across our model. As a result, creditors exercise liquidation rights upon default and the repossessed capital goods end up in the fire-sale market, where they need to be absorbed by a supply of liquidity.

We derive four sets of results. First, our equilibrium has several properties that the literature has traditionally associated with financial crisis. 
Occasionally, the fire-sale market generates sharp and discontinuous drops in prices that adversely affects national output as well. That these events are accompanied by a sharp increase in collateral requirements and some credit rationing suggests a "black hole" interpretation where the price drop is related to liquidity "drying up"; see Morris and Shin (2004). Contagion is another interpretation where a moderate (exogenous) increase in the incidence of financial distress pushes the fire-sale price down, force debtors to pledge a greater fraction of their investment as collateral and increase the incidence of fire-sales even further. For some realizations of the redistributive shock a multiplicity of equilibria emerges, which provides the government with the opportunity to coordinate expectations towards the Pareto-dominating equilibrium - with zero fiscal cost. While such results were derived by other authors (see below), we suggest that they can all be reduced to a simple "abnormality" that appear in the market for liquidity: that both supply and demand are downwards sloping.

Interestingly, the same-slope property of supply and demand can also be interpreted as a multiplier effect, in line with more traditional characterizations of crisis in macroeconomics. In normal circumstances, supply and demand curves slope in opposite directions so as to provide the market with an automatic stabilizer: equilibrium magnitudes vary by less than the underlying shocks. In classroom terminology, shocks create "secondary effects" that operate in the opposite direction to moderate the impact of the original disturbance. In our case, these secondary effects operate in the same direction and intensify impact of the original shock. Contagion is just an application of that characterization to the liquidity market so that the equilibrium response to an exogenous increase in fire sales is even more fire sales.

A related result is that financial crisis is indeed an inherent property of competitive financial markets: the equilibrium probability of a crisis is strictly positive. That is because fire-sales prices are determined by the available "cash in the market": speculators who provide liquidity to the market lose money when prices are stable. Price drops provide them with an opportunity to buy fire-sale assets at a low price and make a profit; to break even ex ante, a crisis must take place with a strictly positive probability; this is already pointed out in Acharya, Shin and Yorulmazer (2009). ${ }^{3}$ It is worth emphasizing that although the entire crisis mechanism of our model (including the same-slope property) deviates from the naive textbook view

\footnotetext{
${ }^{3}$ See also Allen and Gale (1998), Gorton and Huang (2004).
} 
of a market economy, it is firmly grounded in the conceptual framework of neo-classical economics, albeit where markets are affected by contracting and trading frictions.

The second set of results is about the quantitative fit of the model. As noted, we have constructed our model so that most structural parameters have a straightforward, corporate-finance interpretation: rate of return on capital, the incidence of financial distress, leverage etc. Stylized as the model is, our numerical examples yield surprisingly good results: the probability of a crisis is $7.7 \%$, upon which fire-sale prices drop by $39.3 \%$. Due to the strong "synergies" between physical and (entrepreneurial) human capital, repossessions of collateral destroys value. Hence, financial distress involves a real cost to the economy and national output drops $3.9 \%$ during crisis. The credit-crunch aspect of the crisis is highlighted by the cyclical behavior of credit availability. While in "normal" times a company can borrow $\$ 78$ per $\$ 1$ of collateral, during crisis that amount drops to $\phi 40$ per $\$ 1$ of collateral. In our setting financial crisis is always associated with credit rationing, which affects between $1 \%$ and $2 \%$ of borrowers.

The third set of results is about policy. Even after the government coordinates away dominated equilibria, competitive equilibrium still lacks social optimality properties. That is because verifiability problems shut-down potential insurance markets that could avoid financial distress (remember that the shock in our model is purely distributive), and because the price at which lenders are willing to sell repossessed assets does not reflect their "fundamental" value but rather the financial constraint that drives the fire sale. The government can make welfare improvements, but it would be a grave mistake to suppose that the order of magnitude of the welfare improvement is as dramatic as the $39.3 \%$ price drop of capital-goods prices during the crisis. In fact, the ex-ante expected welfare gain over both phases of the business cycle is a tiny one: less than $0.5 \%$. We analyze three alternative policies: liquidity injection to support fire-sale prices, indiscriminate equity injection to strengthen, directly, corporates. balance sheets, and a bailout program that is structured so that only distressed companies have an incentive to apply. We compare the three programs in terms of their effect on welfare and on national debt. With a few modifications to be specified below, the most (least) effective policy is the last (first).

The fourth set of results provides an analysis of the extent to which (de-)regulation affects the systemic nature of crises. We consider our basic economy segregated into two regions. Regulation can then be used to limit 
capital mobility across regions. Alternatively, if one interprets a region as a bank, regulation like "capital requirements" ensures some self sufficiency by making liquidity available for exclusive use in that region (bank). We show that removing such regulatory constraints reduces the overall amount of liquidity available. Although this does not change the probability that at least one region experiences a crisis, it reduces the incidence of systemic crises. On the downside, regulatory constraints increase the equilibrium slack of liquidity in one region. The opportunity cost of such liquidity is therefore higher, and an allocational inefficiency results when one region has surplus liquidity that is not channeled to a region in crisis. The morale, however, is that a systemic crisis is not the fault of liberalization, which uses liquidity interim more efficiently, but of the failure to subsidize the provision of liquidity - a public good in our setting.

\section{Related literature}

There are two main branches of research that are relevant to our paper. Firstly, research that identified a propagation mechanism, whereby shocks affect the price of a production factor, which in turn affects a firm's access to external finance. Bernanke and Gertler (1989) and Kiyotaki and Moore (1997) construct such propagation models that can be interpreted as intertemporal contagion. A transitory technological shock propagates for several periods through its effect on market prices (wages in Bernanke and Gertler and land prices in Kiyotaki and Moore) and thus on entrepreneurial net worth and borrowing capacity. In both of these models, once financial frictions are removed, the propagation effect vanishes. With frictions, the effect dies out eventually. Suarez and Sussman (1997, 2007) use a similar setting in order to generate endogenous, rational expectations, financially driven cycles that may never die out. Fire sales of assets play a pivotal role in generating the necessary price effects: start-ups buy capital goods on the second-hand market from financially distressed companies of the previous generation. ${ }^{4}$ To some extent, the current paper internalizes these dynamic effects into a single period (where the welfare analysis yields sharper results). As we shall see below, the Morris and Shin (2004) model of black holes can be mapped into the same line of ideas though real effects are not emphasized in their paper.

Secondly, there is a literature, starting with Holmstrom and Tirole (1998) and Alan and Gale (1998) that identifies a role for liquidity in a corporate

\footnotetext{
${ }^{4}$ For empirical evidence on fire sales see Pulvino (1998) and Brown (2000).
} 
finance context. Gorton and Huang (2004) summarize the two key ingredients that are necessary for the modeling of liquidity: "first, there must be a need to trade... [and] second, there is a restriction needed, namely, not all assets can be used to purchase all other assets. Buyers must be restricted to making purchases only with certain assets, "liquid" assets. This restriction is akin to a "cash-in-advance constraint". They proceed with a careful and rigorous modeling of how that asset might become scarce during the interim period of trading. As a result of that scarcity, "a liquidity premium can arise in equilibrium" as projects are traded below "fundamental" value so that "the notion of "market efficiency" is altered".

Several authors have already done some work on integrating these two lines of research. One basic finding is that when productive assets change hands at an interim date through a spot market (rather than delivered at an ex-ante contracted price that captures some insurance opportunities), an ex-ante externality arises that leads to overborrowing. This externality has been explored in the context of international finance in a series of papers by Caballero and Krishnamurty $(2001,2003,2004)$ and in a corporate finance context by Gorton and Huang (2004), Lorenzoni (2008) and Acharya, Shin and Yorulmazer (2009). ${ }^{5}$

Our paper differs from the above in several respects. Firstly, in the above papers, the shock that triggers the propagation mechanism is to cash flows generated by investment. In this sense it is akin to a technology shock in the Real-Business-Cycle literature. It is widely accepted, however, that price movements during crisis are far too dramatic to be explained by any technological news. Hence, we took the modeling decision to ignore any technological uncertainty. It follows that an aggregate shock that destroys value for a certain part of the economy must redistribute that value elsewhere. We thus model aggregate uncertainty as a purely redistributive "liquidity" shock that drains capital out of some companies, in favour of others. Through such modeling we try to capture events such as Fisher's debt deflation, a sharp (un-hedged) change in commodity prices, or more topically, a largescale trading loss due to defective risk management. In any event, it follows that the shock creates a simultaneous shortage and surplus of funds in the economy, with exactly equal magnitude; had the Modigliani-Miller Theorem applied to our economy, the shock would have no further macroeconomic

\footnotetext{
${ }^{5}$ See also Fostel and Geanakoplos (2008a) for a more general analysis of efficiency properties of equilibrium in a related setting.
} 
effect. But since we assume that flows of funds are affected by agency problems, the shock destroys value at a macro level. The basic question then, is whether these frictions are sufficiently significant to cause a financial crisis.

A second basic difference between our paper and previous literature is our modelling of the frictions in the access to capital. Much of the existing literature (e.g., Caballero and Krishnamurty (2001, 2003, 2004), Holmstrom and Tirole (1998), Lorenzoni (2008)) model the liquidity demand arising from a need to inject cash in order to continue operating a project. ${ }^{6}$ Frictions arise because only a limited amount of future income is pledgeable by the firm. In contrast, we build on Hart and Moore's (1998) framework which emphasizes the role of collateral, default-triggered repossessions and ultimately fire sales. This framework allows us to identify an important peculiarity in the market for liquidity, namely that demand for liquidity is increasing in its cost (or, as described above, decreasing in fire-sale prices). Hence the already mentioned multiple-equilibria and the black-hole results. ${ }^{7}$

The remainder of the paper proceeds as follows. Section 2 sets out the model. The financial contract is solved for in Section 3 and Section 4 characterizes the economy's equilibrium. We explore welfare and policy implications in Section 5. Section 6 contains an extension in which analyze the implications of market fragmentation and liberalization. Section 7 concludes.

\section{The Model}

We start with a technical account of the assumptions, postponing the discussion of their economic significance to a subsection below. Consider a small, open economy with four periods $t=0, \ldots, 3$ and two types of risk-neutral agents: entrepreneurs and speculators. The former, of which there is a measure of one, has access to the production technology. The latter may supply

\footnotetext{
${ }^{6}$ An exception is Gorton and Huang (2004) who show that a demand for liquidity may arise when entrepreneurs can secretely engage in risk shifting in the interim period. Selling the asset to a better capitalized agent (possibly at a fire-sales price) is a way to prevent risk shifting. While this is an elegant model of liquidity demand, its interpretation as a crisis is less straighforward.

${ }^{7}$ This characteristic of liquidity is reminiscient of the strategic complementarity in liquidity provision identified in a market microstructure context (see Spiegel (1998) and Dow (2004)). More closely related to our approach, Brunnermeier and Pedersen (2008) explore the impact of traders' collateral requirements on liquidity in financial markets. They do not, however, endogenize the collateral constraints.
} 
some of the funding, but its main role is to provide liquidity.

A "company" is defined as a project owned and managed by a single entrepreneur. Companies are set up at $t=1$ when the entrepreneur is endowed with a project and a certain amount of the consumption good, which will be used as the company's internal funding. To operate, the project needs one unit of capital good, which is generated just by investing one unit of the consumption good. A random fraction, $\theta$, of companies have an endowment of $\underline{w}<1$ (fixed deterministically), so that in order to operate they will need external funding. Let $h(\theta)$ be the density function of $\theta$ with a cumulative distribution function $H(\theta)$. Assume that $H(\theta)$ is continuous and strictly increasing on its entire support $[0, \bar{\theta}]$. All other companies have a capital slack with an endowment of $w^{n}$ (a random variable) that is always sufficient to fund them internally. The aggregate endowment $W$ of the corporate sector is fixed (deterministically), namely

$$
W \equiv \theta \underline{w}+(1-\theta) w^{n}=1 .
$$

Notice that equation (1) determines $w^{n}$ as a function of $\theta$ and that $w^{n} \geq 1$ for any realization of $\theta$.

We assume that endowments are non-verifiable. As a result, no insurance scheme - private or public - against capital shortage can be provided. We assume that earnings flows are also non-verifiable, and cannot be pledged to a third party. As a result (see contract section below) the only incentivecompatible form of external funding is a standard debt contract as in Hart and Moore (1998). We denote the fraction of the investment that the company is required to pledge as collateral by $\beta$, which the creditor has the right to repossess at $t=2$ in case the contracted repayment, $R$, is in default. The market for external funding operates at $t=1$ when the expected, risk-free gross lending rate (on loans payable at $t=2$ ) is $\rho_{1}$.

Default is a result of a shortage of liquidity. We assume away any economic distress ${ }^{8}$ : if carried to maturity, all projects can generate the same earning flows, $2 y$. That amount is evenly distributed over the life-cycle of liquid companies: $y$ units of consumption goods at $t=2$ and $y$ units at $t=3$. In contrast, liquidity-short companies earn zero at $t=2$ and $2 y$ at $t=3$. Liquidity shocks are idiosyncratic and take place with a probability of $1-\pi$. Notice the distinction between $t=1$ capital shortage and $t=2$ liquidity

\footnotetext{
${ }^{8}$ An economically-distressed company is one that lacks fundamental value, so that the present value of its earning flow (its going-concern value) falls short of its liquidation value.
} 
shortage.

Due to the strong synergies between real and human capital, collateral repossession destroys value: once a capital good is out of the hands of the original entrepreneur, it only yields $\delta \leq 1$ units of non-verifiable consumption goods at $t=3$. A market for repossessed capital goods, the fire-sale market, opens at $t=2$ and the spot price of is denoted by $q$.

Speculators make their decisions at $t=0$, when they get the opportunity to invest in a riskless but "illiquid" technology that pays $\rho_{0} \in[1, y)$ at $t=3$ per unit invested. The rest is allocated towards liquidity, $F$, that can be used in order to fund companies (at $t=1$ ) or to participate in the fire-sale market. Exiting from the illiquid technology prior to $t=3$, yields a zero payoff. Moreover, we assume that the payoff from that investment is non-verifiable and thus non-pledgeable, so that speculators cannot borrow against the illiquid positions and re-adjust $F$ in subsequent periods. Since speculators' resources at $t=0$ are much larger than our economy's investment opportunity, the supply of liquidity at that point is, effectively, perfectly elastic. However, at $t=1$ the supply is inelastic at $F+W$.

We assume that all communication between debtors and creditors is done through an intermediary, a clearing house, that executes orders conditional on verifiable information but does not make any decisions, nor does it retain any rent. Particularly, the clearing house directs all funding and repayment flows. It also executes asset repossession, in case of default, on behalf of the ultimate creditor. An important assumption about $t=2$ timing of events is that that the clearing house makes repayments to creditors only after the fire-sale market shuts down. We do not allow settlement in kind: rather, all payments should be executed in terms of the consumption good - our model's numeraire. Some readers might wish to interpret the clearing house as a bank, but given its passive nature perhaps such terminology is misleading.

Notice that the $t=2$ of capital-goods price, $q$, can be perfectly anticipated at $t=1$ when $\theta$ is realized and observed. By arbitrage, it follows that the payoff per unit of capital from hoarding liquidity for the fire-sale market equals the expected payoff from providing external funding:

$$
\rho_{1}=\frac{\delta}{q}
$$




\subsection{Discussion of the assumptions}

We model our macroeconomic shock, $\theta$, as being purely redistributive, with no aggregate or productivity implications as in Real-Business-Cycle Theory. We believe that this modelling captures the essence of events that seem to trigger financial crisis. The classic example is already in Fisher's (1933) original analysis: in an economy with (non-indexed) nominal debt contracts deflation (40\% from 1929 to 1933 according to Fisher's Chart I) has indeed impoverished companies of their capital. ${ }^{9}$ At the same time it has enriched bondholders; provided that deflation per se has no adverse effect on real production technology it should have no effect on agents who hold a balanced portfolio. For many years, economists found it hard to believe that a pure redistribution could have such a dramatic effect on the US economy; the purpose of the current modeling is to use modern financial theory to substantiate that argument.

Obviously, nominal price deflation played no role during the recent events. Rather, at some point it became clear that certain financial innovations, that were supposed to spread risks more effectively, taking advantage of changes in regulation, improvements in communication and computing technology and the globalization of financial markets, have not performed in practice as well as it was hoped for. It also became clear that not all sections of the system are equally exposed to the faulty design. In such a situation, the realization that one part of the system is heavily exposed should have been good news to the other parts, for then the misallocated risk is not on the others' balance sheet. Yet, such news pushed the entire market into a crisis situation; see Lehman Brothers in the recent crisis, or LTCM in the crisis of 1998. Hence, the question is how do pure redistributive shocks create real adverse effect, endogenously. Needless to say, we recognize that in reality there are aggregate-technological shocks as well, which may be correlated with the financial shocks. Our decision to ignore this source of uncertainty is both for analytical clarity and in order to see how far redistributive shocks can go in terms of generating plausible quantitative results.

On top of being deterministic, we also assume that aggregate wealth, $W$,

\footnotetext{
${ }^{9}$ The reason why indexation is absent is important. In this paper we shut-down this market by the non-verifyability of capital assumption. In Suarez and Sussman (2008) the market shut-down is explained by the endogenous-cycles mechanism: since the (intergenerational) redistribution (and the entire cycle) are deterministic, insurance opportunities are eliminated by the Hirshleifer effect.
} 
equals to 1, the same size as the economy's total investment opportunities. That is partly for analytical convenience, for then even for small $\theta \mathrm{s}, w^{n}$ exceeds 1 and the corporate sector is cleanly separated into capital short and capital slack companies. It is also a realistic assumption: empirical flow-of-funds studies reveal that on aggregate the corporate sector is close to self-sufficiency in capital, so that investment is largely internally funded on an aggregate level; see Mayer (1988). That implies very substantial flows of capital within the corporate sector that are either intermediated by the financial industry or made directly, e.g., via trade credit.

Just as we abstract from real shocks on the aggregate level, we ignore economic distress on the corporate level: potentially, all companies can generate the same earnings flow. (In equilibrium, some are liquidated prematurely as a result of the non-observability problem.) Again, we recognize that there are economically distressed companies in the real world, that would be liquidated even in a frictionless capital market where the Modigliani-Miller Theorem holds. Surely, had we included real economic shocks in our setting, we could model their correlation to the incidence of economic distress. Yet, we focus here on the "inefficient" liquidation of economically-viable companies. It seems to us that most of the current policy issues - like bailouts or liquidity provision - are related to concerns about that type of liquidation.

Clearly, the non-verifiability assumption plays a central role in the analysis. Non-verifiability of initial wealth endowments implies that there is no insurance market against capital shortages. Due to the non-verifiability of earnings flows, debt repayments can be collected only under threat of repossession; as a result, the creditor cannot leave debt repayments to $t=3$ (see contract section below). Moreover, since the maturity value of repossessed capital goods is also non-verifiable, the ultimate creditor cannot leave the repossessed assets with the clearing house until $t=3$ and insists on settlement at $t=2$. Basically, by the end of period 2 all assets need to rest with their ultimate beneficiary, for any further transfers are undermined by nonverifiability. All that generates a need for immediacy in trading, a property that all theories of liquidity share. Interestingly, in Diamond and Dybvig (1983) that is done through the non-verifiability of consumption needs. Our analysis links the verifiability problem more tightly with standard debt contracts that appear to have played a pivotal role in the recent crisis.

The assumption that settlement in kind is disallowed is the standard Clower constraint that "money buys goods ... but goods don't buy goods". Unlike in standard cash-in-advance models, our numeraire is a commodity 
and liquidity is held by specialized intermediaries (speculators). The slight complication with asset repossession is that it resembles settlement in kind: the creditor is satisfied with a commodity other than the consumption good. We thus introduce the assumption of a clearing house, which repossesses the asset on the creditor's behalf, exchange it for the consumption good and then compensates the creditor. ${ }^{10}$ Notice that the assumption of repossession/liquidation by a specialized intermediary is actually a realistic one. In most countries where the rule of law prevails creditors do not take possession of assets in default directly. The task is delegated to a specialized intermediary, a receiver. ${ }^{11}$ Usually, the receiver is obliged by law to auction off the assets so as to satisfy fair-value requirements: that he can verify that the distribution of the liquidation value among the creditors was according to their respective rights (namely, their absolute priority), which requires a market test and a valuation in a single unit of account.

Lastly, the assumption that the clearing house delays debt repayments until after the fire-sale market is closed implies that funds cannot be used first to finance companies and then again to bid for fire-sale capital goods. Hence, liquidity providers needs to make a portfolio decision (at $t=1$ ) and allocate their funds between funding companies or absorbing fire sales, which seems realistic. We shall comment further on this assumption in Section 3.1 below when we parameterize the model.

\section{The contract}

Consider the case of a capital-short company with wealth $\underline{w}<1$. It will need external finance. As in Hart and Moore (1998) earnings flows are assumed to be non-verifiable, and it is therefore impossible to entitle external investors to a share of the earning. They can only be compensated by setting the company a repayment target and threatening it with repossession in case it does not meet the target, namely a standard debt contract $(R, \beta)$.

Consider first a financially viable, liquid company (earning $y$ in both $t=2,3)$. Clearly, payments cannot be delayed to $t=3$, for then the assets

\footnotetext{
${ }^{10}$ The assumption that credit flows from speculators to entrepreneurs are intermediated is similar to the assumption made in the recent 'limits-to-arbitrage' literature (see Gromb and Vayanos, 2002), where trades between two islands have to be intermediated by an arbitrageur.

${ }^{11}$ See Franks and Sussman (2005) for more detail.
} 
have already depleted and the threat of repossession is empty. Even at $t=2$, repayments are subject to the constraint that the company has no incentive to renegotiate a lower repayment. Renegotiations are modelled as a Nash bargaining game: with a probability $\lambda$ the clearing house (on behalf of the creditor) can make a take-it-or-leave-it offer to the company. If the offer is rejected, the creditor can exercise his liquidation rights. The creditor's equilibrium offer is thus the opportunity cost of the assets to the debtor, $\beta y$. With probability $1-\lambda$ the firm makes a take-it-or-leave-it offer, which (by a similar argument) would be as low as the liquidation value $q \beta$. It follows that the repayment, $R$, has to satisfy an incentive compatibility constraint (IC)

$$
R \leq \beta[(1-\lambda) q+\lambda y] .
$$

Subject to the IC, liquid companies repay their debt, leaving the threat of liquidation and contract renegotiation off the equilibrium path.

Consider now a financially distressed company (earning zero at $t=2$ ad $2 y$ at $t=3$ ). Clearly such a company has no way to precommit to a payment at $t=3$, and no liquidity to execute payment at $t=2$. At the same time the creditor has no incentive to forgive payment, so it will exercise its repossession rights. It follows that the creditor's participation constraint $(\mathrm{PC})$ is

$$
\pi R+(1-\pi) \beta q=\rho_{1}(1-\underline{w}) .
$$

The PC holds with equality due to the scarcity of entrepreneurship and the ensuing competition among creditors. The contract also needs to satisfy the feasibility constraints

$$
R \leq y, \text { and } \beta \in[0,1] .
$$

Now, the contract problem is to maximize the entrepreneur's value (at $t=3)$ subject to the various constraints above:

$$
\begin{aligned}
& \max _{R, \beta} \pi(2 y-R)+(1-\pi)(1-\beta) 2 y, \\
& \text { s.t. }(I C), \quad(P C), \quad(F C) .
\end{aligned}
$$

(We deal with the companies' participation constraint, both capital slack and capital short, below.) Substituting (PC) into the objective function and re-arranging, we express the final value of a capital short company in terms of $\beta$ alone:

$$
\left.V\right|_{\underline{w}}=2 y-\rho_{1}(1-\underline{w})-(1-\pi) \beta(2 y-q) .
$$


Hence, the final value is the company's "fundamental" value $2 y$, minus the cost of external funding, minus the dead-weight loss of external funding, which is the probability of distress, $(1-\pi)$, times the fraction of the project that is collateralized (and repossessed in distress), $\beta$, times the deadweight loss per unit of capital liquidated $(2 y-q)$. Clearly, the smaller $\beta$, the higher is the entrepreneur's value.

Lemma 1 Let

$$
b=\frac{\rho_{1}(1-\underline{w})}{q(1-\lambda \pi)+\lambda \pi y} .
$$

If $b \leq 1$, the optimal contract is $\beta=b$; if $b>1$, the capital-short companies cannot obtain external funding.

Proof. It follows from the discussion of (4) that the solution of the contracting problem is the minimal $\beta$ within the problem's feasible set. The (PC) is a downwards-sloping line in the $(R, \beta)$ space; the (IC) is an area above an upwards-sloping line in the same space. Hence, the minimal point that satisfies both (IC) and (PC) is the intersection point between the two when the former holds with equality. That point is defined by equation (5). If $b \leq 1$, then (5) also defines the optimal contract; if $b>1$ the feasible set is empty and the company cannot obtain any funding.

Now substitute the arbitrage condition (2) into equation (5) to obtain $b$ as a function of $q$ alone: $b(q)$. Clearly, companies need to pledge a greater fraction of their investment as collateral when fire-sale prices, $q$, drop. ${ }^{12}$ Pressures come from both the PC and the IC. As for the former, when distressed assets sell at a lower price, more needs to be sold so that the creditor can break even. At the same time, the opportunity cost of funding, $\rho_{1}$, increases, because speculators and capital-slack companies (i.e. companies with $w^{n}>1$ ) can earn a higher rate of return by holding their funds to the next period and buy fire-sale assets at a low price. That increases the risk-free cost of lending. Moreover, with a lower fire-sales price the threat of repossession is less effective in forcing debtors to repay their debts, rendering the (IC) more stringent. So for both reasons, collateral requirements increase. Since all pledged assets of distressed companies are repossessed and then sold off, it follows that the volume of liquidations, $\theta(1-\pi) \beta$, increases when fire-sale prices drop. Moreover, substituting (2) into (5), it is clear that the value

\footnotetext{
${ }^{12}$ Remember that the aggregate shock $\theta$ is observed and the equilibrium price $q$ rationally anticipated when financial contracts are signed.
} 
of repossessed assets, $q \times \theta(1-\pi) \beta$, also increases when the fire-sale price drops. Hence, the demand for liquidity is downwards sloping in $q$, which will play a pivotal role in the equilibrium analysis below.

Let $\underline{q}$ be the positive root of $b(q)=1$ :

$$
\underline{q}=\frac{-\lambda \pi y+\sqrt{(\lambda \pi y)^{2}+4(1-\lambda \pi) \delta(1-\underline{w})}}{2(1-\lambda \pi)} .
$$

If prices ever drop that low, a credit-rationing equilibrium generically occurs. Clearly, prices cannot get lower than that. For then, creditors cannot recover a market return even at the highest feasible $\beta$. The only way to avoid this outcome is to deny credit to some companies at a (gross) riskless rate of $\delta / q$. Let $\mu$ be the probability of obtaining credit. Clearly, if $q>\underline{q}, \mu=1$; if $q=\underline{q}, \mu \in[0,1]$, to be determined endogenously in equilibrium. Notice that our assumptions do not prevent credit-rationed companies from lending their endowment to other companies at the market rate.

Now consider the case of a capital-slack company with $w^{n}>1$, so that the project is internally financed $(\beta=0)$ - in line with the "pecking order" theory. The entrepreneur's final value is now $2 y+\left(w^{n}-1\right) \rho_{1}$. Using the arbitrage condition in (2) we can express companies' expected final value whether it is short of capital or not - and for a general endowment $w \in$ $\left\{\underline{w}, w^{n}\right\}$ as:

$$
\begin{gathered}
V=w \frac{\delta}{q}+\mu S, \\
S=\left(2 y-\frac{\delta}{q}\right)-(1-\pi) \frac{\frac{\delta}{q}[1-\min (1, w)]}{q(1-\lambda \pi)+\lambda \pi y}(2 y-q) .
\end{gathered}
$$

It is convenient to think of the final value as the sum of endowment wealth (including interest), $w \rho_{1}$, plus the rent, $S$, generated by entrepreneurial skill. The rent equals the value of the technology, net of the opportunity cost of capital, less the deadweight loss of external funding (in case that is needed). Crucially, in a model with financial frictions the value of the rent is not just a technological function, it also depends on the entrepreneur's initial wealth and on the fire-sale price, $q$.

Now that we have expressed the lowest conceivable equilibrium price, $\underline{q}$, in terms of the model's structural parameters, we can use it in order to lay down two additional parametric assumptions that guarantee the existence of 
equilibrium. ${ }^{13}$ Firstly, speculators will not participate in the fire-sale market if prices are above $\delta$, for then the return on holding liquidity at date zero is higher than the highest possible return on liquidity. At the same time, the contract requires that fire-sale prices are (weakly) above $\underline{q}$. We therefore assume that

$$
\frac{\delta}{\underline{q}}>\rho_{0}
$$

Since $\rho_{0}>1$ assumption (A1) guarantees that $\underline{q}<\delta$ so that the set of feasible equilibrium prices is $[\underline{q}, \delta]$ is non-empty.

Secondly, we still have to check that it is in the entrepreneurs' best interest to operate their projects rather than invest their wealth at the market rate. Given expressions (7) and (8) it is clear that participation requires that the rent for entrepreneurial skill, $S$, is positive for both $\underline{w}$ and $w^{n}$ for any price in $[\underline{q}, \delta]$.

Lemma $2 \pi 2 y-\frac{\delta}{\underline{q}} \geq 0$ is a sufficient condition for $S>0$, at any feasible equilibrium price.

Proof. It follows from equation (8) that $S$ is increasing in $q$ and that the rent for capital-slacked companies is greater than the rent for capital-short companies. Hence, a sufficient condition for a positive rent at any feasible equilibrium price is that the rent for capital short companies at $q=\underline{q}$ is positive. Substituting $w=\underline{w}$ and $b(\underline{q})=1$ into equation (8) we derive the condition above.

We thus assume that

$$
\pi 2 y-\frac{\delta}{\underline{q}} \geq 0
$$

Notice the intuitive interpretation of assumption (A2): in a complete markets/contracts world a positive NPV for the technology is sufficient in order to guarantee the entrepreneur's participation (remember that $\rho_{1}=\frac{\delta}{q}$ ). In our setting, a stronger condition is required in order to account for the loss of value due to financial distress.

\footnotetext{
${ }^{13}$ Any macro model needs to make assumptions that guarantee the existence of a price at which buyers and sellers are willing to trade. In standard models that is done via the Inada conditions. In their stead, specific parametric assumptions are necessary in our model.
} 


\subsection{Model parameterization}

To illustrate our results, we carry through the paper a numerical example. While our model is too crude to be considered a calibration, we hope that keeping the structural parameters within a "realistic" order of magnitude provides at least a preliminary idea about the quantitative fit of the model. We turn next to a brief discussion of the chosen parameters, which are listed in Table 1 below.

We think of the time horizon of our model, from $t=0$ to $t=3$ as a five-year period. Needless to say, the time index, $t$, indicates decision and trading events rather than equally-spaced points within a five-year interval; for example, the production period $t=1$ to $t=2$ is probably much lengthier than, say, the time between $t=0$ and $t=1$.

We assume that $y=1.25$ which implies an internal rate of return (IRR) on investment of around $20 \%$ per annum. This is, of course, way above the $8 \%$ order of magnitude that would be consistent with the macroeconomic data, more in line with the high-end of venture-capital activity. It seems, however, that policy is concerned that distressed liquidations tend to affect activity that is significantly more productive than the national average. More so, if part of the loss comes in the form of "private benefits" that have no expression in the financial statistics. Since one of the main objectives of the numerical examples is to put an upper bound on the value of policy, we prefer to over-account for loss of value due to "inefficient" liquidations.

Bankruptcy statistics is not a good source for the financial-distress parameter, $1-\pi$. Many bankruptcies are actually voluntary liquidations (that do not involve financial distress), while many distress events are worked out informally, usually requiring that the creditor takes a "haircut". In order to determine a realistic value of $1-\pi$, we use the following argument: since the early 1980's, the mean annual write-off rate for US commercial banks has been about 1\%. ${ }^{14}$ Assuming an average recovery rate of about $80 \%{ }^{15}$ we conclude a $5 \%$ incidence of financial distress per annum, so $25 \%$ over the 5 year period.

Our parameterization of $\underline{w}$ implies that leverage (debt to total assets) for capital-short companies is $40 \%$; leverage for capital-slacked companies is obviously zero. Given the parametrization of $\bar{\theta}$, mean leverage for the entire

\footnotetext{
${ }^{14}$ See "loan and lease charge off" against the balance-sheet value of loan and lease in FDIC statistics.

${ }^{15}$ See Franks and Sussman (2005).
} 
population is between zero and 16\%. Rajan and Zingales (1995) report mean book (market) leverage (debt to net assets) for listed companies between $38 \%$ (27\%) in the United States to 25\% (19\%) in Germany. Since their own findings show that leverage tends to increase with size, leverage for nonlisted companies are probably smaller. Our parameterization of $\delta$ and $\rho_{0}$ is standard; for $\lambda$ and the distribution function $h(\theta)$ we have no supporting data.

In light of these assumptions, it is worth pointing out another motivation for the previous section's assumption that the clearing house delays payments to creditors until the fire-sale market shuts down. According to our parameterization, no more than $10 \%$ (namely $\bar{\theta}(1-\pi)$ ) of capital stock is actually repossessed at $t=2 .{ }^{16}$ At the same time, $37.5 \%$ (namely $(1-\pi) / 2$ ) of the five-year potential output has already been produced, and is available in the form of consumption goods. Obviously, it would be unrealistic to assume that all that amount is available to bid for fire-sale assets. Rather, we assume that consumption goods can be directed to the fire-sale market only with a certain lag, so that liquidity needs to be earmarked for that purpose one period ahead of market opening.

Table 1

Structural parameters for the numerical examples below.

\begin{tabular}{lcc}
\hline \hline Description & Model's notation & Parameterization \\
\hline Project parameters & $2 y-1$ & $150 \%$ \\
IRR & $1-\pi$ & $25 \%$ \\
prob. liquidity shortage & $1-\underline{w}$ & $40 \%$ \\
capital shortage & $\delta$ & $50 \%$ \\
depreciation & $\lambda$ & $50 \%$ \\
bargaining power & & \\
Market parameters & $\rho_{0}-1$ & $5 \%$ \\
ex-ante riskless rate & $\bar{\theta}$ & $40 \%$ \\
worse-case incidence of shortfall & $h$ & uniform \\
distribution of $\theta$ &
\end{tabular}

\footnotetext{
${ }^{16}$ This number seems realistic. According to Kiff and Klyuev (2009), the rate of morgage "foreclosure starts" is about $2 \%$ per annum of morgages outstanding (by number) during normal times and double that amount during the recent crisis. Notice, however that not all houses are mortgaged (perhaps $70 \%$ in the US). Also, it is smaller homes that tend to be foreclosed, which means that, by value, foreclosure rates are lower than the number above.
} 


\subsection{Discussion and numerical example}

Using the parameters above, we plot in Figure 1 the entrepreneur's rent, $S$, as a function of $q$ for both types of companies in the model. As mentioned, the graph of an externally funded (capital-short) company lies below the graph of an internally-financed company. Clearly, the model's parameterization does not violate assumptions (A1)-(A2). The vertical segment corresponds to different values of $\mu$. At $\mu=0$ a financially constrained entrepreneur gets no credit so his surplus falls to zero.

A basic intuition for the workings of the model can already be acquired at this point. Consider a redistribution of $\$ 1$ from a capital-short company to a capital-slack company, holding the liquidation price at its highest possible level: $q=\delta=0.5$. As a result, aggregate rent would fall by $\phi 64$. This is because the extra wealth does not generate any rent (above market return) in the hands of the capital-slack company; however, once a company becomes capital short, it needs to fund externally and pledge a fraction $\beta$ of its investment as collateral. That fraction will be repossessed in case of liquidity shortage, destroying value.

At a lower $q$, rents are lower for both types because the opportunity cost of capital, $\rho_{1}$, is higher (see Figure 1). Yet the gap between the two increases as well. As a result, a redistribution of $\$ 1$ from a capital-short company to a capital-slack company at a fire-sale price of $q=\underline{q}$ would result in a loss of output of $\$ 1.37$. 


\section{Figure 1}

The entrepreneur's rent, $S$, for internally funded (capital slack) and externally funded (capital short) companies. For structural parameters, see Table 1.

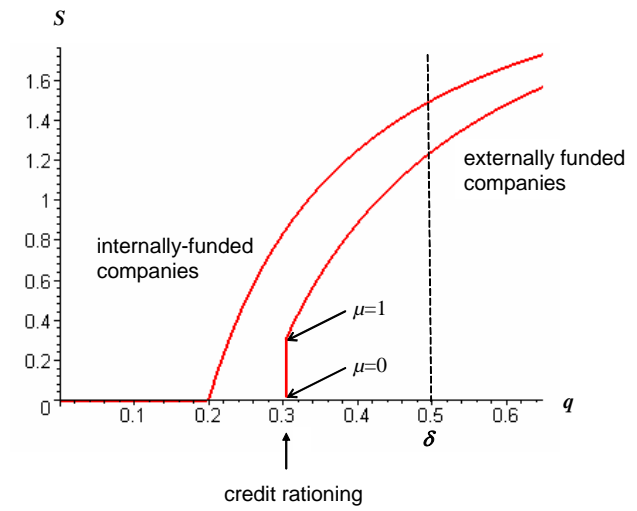

\section{Competitive equilibrium}

We take two steps in characterizing the competitive equilibrium. First, we analyze the ex-post market for liquidity, where $F$ is predetermined and $\theta$ is already realized. Second, we analyze the determination of $F$ at $t=0$. We then discuss the economic significance of the results and carry the parameterization above into a numerical example of the equilibrium.

\subsection{The ex-post market for liquidity}

The ex-post market for liquidity is actually an aggregation of two spot markets. First, at $t=1$, capital-slack companies are funded. Then, at $t=2$, fire-sales are absorbed by market liquidity. Given that the prices in these markets are linked via a simple arbitrage condition (2), equilibrium is determined by a single market-clearing condition:

$$
F+\left(w^{n}-1\right)(1-\theta)+\theta(1-\mu) \underline{w}-\theta \mu(1-\underline{w})-\theta \mu q(1-\pi) b(q) \geqq 0 .
$$

On the supply side we have speculators, capital-slack companies supplying $\left(w^{n}-1\right)$, and a fraction, $(1-\mu)$, of the capital-short companies who happen 
to be credit-rationed and are thus willing to lend their wealth endowment at the market rate. On the demand side, there are the capital-short companies who are not credit rationed. The last term in equation (9) comes from the fire-sale market. There are $\theta$ capital-short companies, of which a fraction $\mu$ actually get funded. Of this population, a fraction $(1-\pi)$ will be short of liquidity and will have no other option but to default, in which case it is in the creditor's best interest to exercise his contractual right and repossess a fraction $b(q)$ of the investment. Due to the assumption that repossessions are executed by an intermediary (the clearing house) and that payment in kind is disallowed, an amount $\theta \mu(1-\pi) b(q)$ of repossessed capital goods is driven into the fire-sale market. The amount of liquidity that is required in order to absorb it is that amount times the fire-sale price, $q$. Since there might be more liquidity available than demand, the clearing condition might hold with inequality, where the supply of liquidity is greater then the demand.

Using (1) we can rewrite the clearing condition (9) as

$$
F+W-(1-\theta)-\theta \mu[1+q(1-\pi) b(q)] \geqq 0 .
$$

Proposition 1 There exists an ex-post equilibrium in the market for liquidity, with three possible regimes:

- If $\theta<\frac{F+W-1}{\underline{q}(1-\pi)}$ then there is a unique equilibrium with a slack of liquidity: $q=\delta, \bar{\mu}=1$.

- If $\frac{F+W-1}{\underline{q}(1-\pi)} \leq \theta \leq \frac{F+W-1}{\delta(1-\pi) b(\delta)}$ there are multiple equilibria as follows: (i) $q=\delta$ and $\mu=1$, (ii) $q \in(\underline{q}, \delta)$ and $\mu=1$, (iii) $q=\underline{q}, \mu<1$.

- If $\theta>\frac{F+W-1}{\delta(1-\pi) b(\delta)}$ then there is a unique credit-rationing equilibrium: $q=\underline{q}, \mu<1$.

In a credit rationing equilibrium (either the second or the third regime) the amount of credit rationing is:

$$
\mu=\frac{F+W-(1-\theta)}{\theta[1+\underline{q}(1-\pi)]} .
$$

Proof. When liquidity is slack speculators bid-up the fire-sale price to $\delta$ and still there is enough funding for all companies, so $\mu=1$. Clearly

$$
F+W-1-\theta[1+\delta(1-\pi) b(\delta)] \geqq 0 .
$$


When this condition fails, and since $q b(q)$ is decreasing in $q$ - see equation (5) - the market-clearing condition cannot hold with $\mu=1$ for any other price in $[\underline{q}, \delta]$. Hence the critical point, $\frac{F+W-1}{\delta(1-\pi) b(\delta)}$, so that for any $\theta$ above, credit rationing is the unique equilibrium.

In a credit-rationing equilibrium the fire-sale price drops to $\underline{q}$ and

$$
F+W-1-\theta[1+\underline{q}(1-\pi)] \leqq 0
$$

remember that, by construction, $b(\underline{q})=1$. Consider the point where that condition holds with equality so that credit-rationing just appears. Since $q b(q)$ is decreasing in $q$, there must also be a liquidity-slack equilibrium. Hence the critical point $\frac{F+W-1}{q(1-\pi)}$ so that for any $\theta$ below, the liquidity slack is the unique equilibrium.

Due to assumption (A1) the second critical point is greater than the first. It follows that in between there are multiple equilibria with either credit rationing, liquidity slack or a fire sale price in $(\underline{q}, \delta)$ where the market-clearing condition (10) holds with equality for $\mu=1$.

Substituting $q=\underline{q}$ into the market-clearing condition (10) we can solve for the fractions of companies that are credit rationed, or the unconditional probability of being credit rationed.

Figure 2 provides a diagrammatic exposition of the equilibrium and the existence argument in Proposition (1). The supply of liquidity is the inverted L-shaped graph, $\delta$ horizontally and $F+W$ vertically. As noted the demand for liquidity is decreasing in the fire-sale price, $q$. Three possible realizations of $\theta$ are plotted: for the low and high realizations there is a unique equilibrium at points $B$ and $C$, respectively, while for the interim realization there are multiple equilibria at points $A, A^{\prime}$ and $A^{\prime \prime}$, one with $q=\delta$ and a slack of liquidity, one $q \in[\delta, \underline{q}]$ and market clearing, and one with $q=\underline{q}$ and credit rationing, respectively. (Notice that points $C$ and $A^{\prime \prime}$ are not quite equilibrium points: they represent the equilibrium price but not the quantity, which is somewhere between these points and $F+W$, depending on credit rationing.) 


\section{Figure 2}

The ex-post market for liquidity

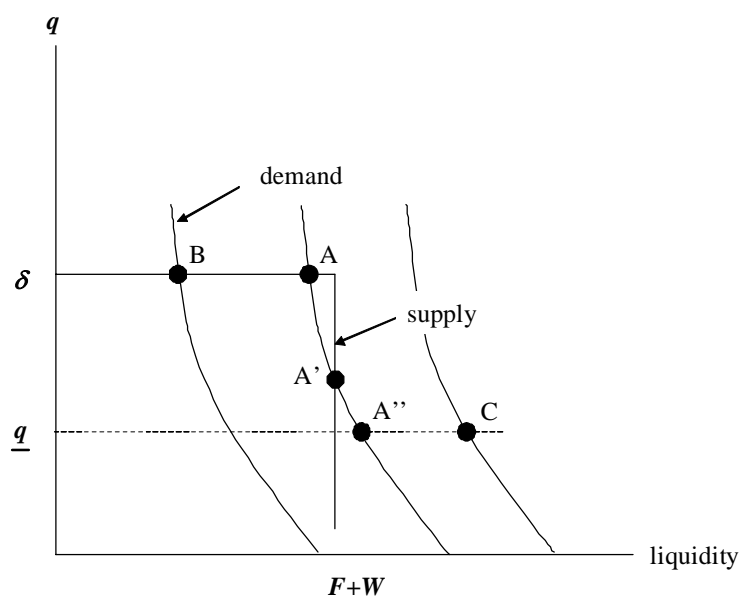

Since asset repossession destroys value the three equilibrium in Figure 2 are Pareto ranked: point $A$ dominating points $A^{\prime}$ and $A^{\prime \prime}$. Hence, the government should try to coordinate expectations towards point $A$. We thus show:

Proposition 2 In case of multiple equilibria, a policy that guarantees a firesale price of $\delta$ eliminates the Pareto-dominated equilibrium points at a zero fiscal cost to the government.

Proof. Let $q^{e}$ be the expected fire-sale price. Then, equilibrium is determined by substituting

$$
b_{G R}=\frac{\frac{\delta}{q^{e}}(1-\underline{w})}{q^{e}(1-\lambda \pi)+\lambda \pi y}
$$

into the equilibrium condition (10). Clearly, the demand for liquidity is no longer sensitive to the actual market price, $q$. Hence, if for a certain realization of $\theta, \delta$ was one of a few equilibrium prices, it is the unique equilibrium if $q^{e}=\delta$. Since there was enough liquidity to fund companies and absorb fire sales at a price of $\delta$ when expectations were not fixed, $\delta$ will be the actual fire-sale price when $q^{e}=\delta$. In such a case, if the government guarantees a 
price of $\delta$, the holders of the guarantees will not exercise their option and the fiscal cost of the policy to the government is zero. Hence, the policy is credible and, indeed, $q^{e}=\delta$. Notice that this argument does not hold for $\theta$ s where $q$ is the unique equilibrium price (without price guarantees).

From this point onwards we shall assume that the government always implements a zero-cost policy that eliminates Pareto dominated equilibria via coordination of expectations. As a result, there is a unique critical point,

$$
\theta^{*}=\frac{F+W-1}{\delta(1-\pi) b(\delta)}
$$

credit-rationing equilibrium appears when $\theta>\theta^{*}$.

Lastly, and in order to improve the macro interpretation of the model we calculate the Gross Domestic Product (GDP), $Y$, as it should be measured in our model:

$$
Y \equiv(1-\theta) 2 y+\theta \mu[2 y-(1-\pi) b(q)(2 y-\delta)]+\theta(1-\mu) .
$$

It is "gross" in the sense that depreciation is netted out, and "domestic" in the sense that interest payments to foreigners (speculators) are excluded.

\subsection{The ex-ante equilibrium: speculators' choice}

Speculators allocate their funds at $t=0$ so as to maximize their expected date 3 payoff. It follows immediately that

Proposition 3 Given assumption (A1) and the implementation of policies to coordinate expectations as suggested by Proposition 2, there exists a unique competitive equilibrium. The amount of liquidity held by the market, F, satisfies

$$
H\left(\theta^{*}\right)+\left[1-H\left(\theta^{*}\right)\right] \frac{\delta}{\underline{q}}=\rho_{0},
$$

and there is a strictly positive probability of a financial crisis.

Proof. First, notice that the expected return on investing in liquidity is given by $E\left(\rho_{1}\right)=H\left(\theta^{*}\right)+\left[1-H\left(\theta^{*}\right)\right] \frac{\delta}{q}$, which is strictly decreasing in $F$ and is equal to $\frac{\delta}{q}$ for $F=0$. If $F$ is small (large) so that $E\left(\rho_{1}\right)>\rho_{0}\left(E\left(\rho_{1}\right)<\rho_{0}\right)$ this cannot be an equilibrium since more (less) speculators would invest in 
the liquid asset. Hence, $\theta^{*}$ is uniquely given by the solution to (13) and $F$ is determined by equation (12). Notice that the probability of a financial crisis is $\left(\rho_{0}-1\right) /\left(\frac{\delta}{q}-1\right)$, independently of $h$.

\subsection{Discussion and numerical example}

Many of the properties of our model can be traced back to a single "abnormality" in the market for liquidity: both supply and demand are decreasing in the fire-sale price, $q$. To start with, equilibrium has a contagion property: consider a realization of the shock $\theta$ just below $\theta^{*}$. A small increase in the level of the shock to $\theta>\theta^{*}$ results in substantially higher losses not just for the additionally-distressed companies, but also for the entire population of financially distressed companies, much like in a "domino effect". The mechanism is already discussed above: lower fire-sale prices imply increased collateral, more equilibrium fire sales and a greater disruption of production. Notice that our formalization does not require that markets are segmented in a way that forces market participants to take large and non-diversified positions on the risk of their neighbors. Rather, lenders and borrowers are coordinated into a larger exposure to credit risk via a market price that is determined in a competitive, atomistic market. ${ }^{17}$

The "multiplier effect" is an intimately related phenomenon: at the contagion point the equilibrium quantity is a (greater than one) multiple of the original shock. That is in contrast to a "normal" market where supply and demand slope in opposite directions so that equilibrium magnitudes vary by less than the underlying shocks. In other words, in a normal market shocks create "secondary effects" that operate in the opposite direction to moderate the impact of the original disturbance to provide an automatic stabilizer. Both contagion and the amplification of shocks are related to Morris and Shin's (2004) "black holes", which they characterize as sharp and discontinuous price changes, propelled by an "endogenous feedback mechanism" where "market distress can feed on itself". Much "like a tropical storm [black holes] ... appear to gather more energy as they develop". We extend this approach by endogenizing the interaction between anticipated fire-sales prices and the optimal financial contract and show that it gives rise to a feedback effect.

\footnotetext{
${ }^{17}$ Fostel and Geanakoplos $(2008 \mathrm{~b})$ provide a general equilibrium model with heterogenous agents and incomplete markets, in which one group of agents is overexposed to a risky asset. This can create contagion to another, fundamentally unrelated risky asset.
} 
Clearly, when supply and demand are both (weakly) decreasing in price, multiple equilibria may arise. Unlike in Diamond and Dybvig (DD), our model does not rely on any "defective" financial instrument (demand deposits with their built-in first-mover advantage). However, like in DD, the government can coordinate expectations towards one of the equilibrium points and improve welfare. Policy instruments are also similar: deposit insurance in DD and credit guarantees in our model. In both their model and ours the fiscal cost of eliminating dominated equilibria is zero. Nevertheless, there is a fundamental difference between the DD model and ours: unlike in DD, in our model coordination failures are a side-effect of a more fundamental market failure. Consequently, eliminating the multiplicity will not restore the first best. Also, in our setting multiple equilibria appear at intermediate levels of the liquidity shock, $\theta$, but vanish as the shock intensifies. While welfare-improving policies still exist for higher $\theta$ s (see below), these policies will involve a fiscal burden. Hence, a possible explanation for the different experience of the crisis of 1998 and now.

Another interesting property of the equilibrium is that it generates, simultaneously, liquidity hoarding and credit rationing. At $t=1$ liquidity providers hoard liquidity in order to participate in the fire-sale market at $t=2$, which at such times offers above normal rates of return. At the same time, some capital-short companies are denied credit as creditors perceive that any attempt by these companies to bid-up the riskless rate would violate incentive compatibility and participation constraints.

In Table 2 we present equilibrium magnitudes computed for the parameterization from Table 1. Where possible we list the actual data based on the most comprehensive survey of financial crisis to date: Reinhart and Rogoff $(2008,2009)$. Stylized as it is, our model shows surprising quantitative fit. At the contagion point, $\theta^{*}$, the price of repossessed capital goods will drop by almost $40 \%$. As a result, credit availability falls sharply: in normal times companies can borrow $\& 78$ on a dollar of collateral but during a crisis they can borrow only $\$ 40$ on a dollar of collateral. As a result, repossessions destroy more value. At the critical $\theta^{*}, G D P$ will drop discontinuously by $3.9 \%$. The number might seem small given the massive loss of value at the corporate level upon liquidation. Notice however that although up to $40 \%$ of companies can be short of capital, only $25 \%$ of them become financially distressed (remember that internally-financed companies avoid financial distress even if short of liquidity). While our predicted fall may seem small, the order of magnitude is not unrealistic. (It is not entirely clear how to fit 
the evidence provided in Reinhart and Rogoff into the frequency of our data; hence the relatively-wide range in the actual numbers). Credit rationing will appear during financial crisis, but the magnitude is not substantial, between $1.1 \%$ and $1.6 \%$, depending on $\theta$, which implies a relatively steep demand for liquidity (see Figure 2).

The probability of a crisis is only $7.7 \%$, not far away from Bagehot observation: "every ten years or so", and even closer to the actual data. Hence, financial crisis is part of the "normal" functioning of a competitive capital market: speculators lose money in normal times and profit in crisis. In a competitive market they have to break even, which implies an equilibrium crisis. It remains to be seen whether this competitive equilibrium is efficient, i.e. whether the loss of value in crisis is also a market failure.

In order to get some idea of the robustness of the numerical results with respect to underlying parameters, we conduct a sensitivity analysis. The upshot of it is that the orders of magnitude of our results are not affected by small modifications of the parametric assumptions. Details of this analysis are provided in the Appendix.

\section{Table 2}

Competitive equilibrium, numerical example. For structural parameters see Table 1.

Source for actual data is Reinhart and Rogoff (RR), from top to bottom: $(a)$ peak-to-trough

house and equity price decline, RR (2009) Figures 1 and 2; (b) calculations based on depth and duration of GDP decline, annualized (left) or stretched over a five-year period relative to a growth trend of $2 \%$ per annum (right), RR (2009) Figure 4 ; $(c)$ share of years in banking crisis, RR (2008) Table 5a.

\begin{tabular}{lccc}
\hline \hline Description & Model & Values & Actual data \\
\cline { 1 - 3 } Competitive equilibrium & $\frac{q}{\bar{\delta}}-1$ & $-39.3 \%$ & $-35.5 \%,-55.9 \%(a)$ \\
price drop in crisis & $\frac{(1-\underline{w})}{b(\delta)}, \frac{(1-\underline{w})}{b(\underline{q})}$ & $78 \%, 40 \%$ & - \\
loan to security & $\left.Y\right|_{q=q} /\left.Y\right|_{q=\delta}-1$ & $-3.9 \%$ & $-3.5 \%,-8.8 \%(b)$ \\
output drop at $\theta^{*}$ & {$\left[1-\mu\left(\theta^{*}\right)\right]$} & $1.1 \%$ & - \\
credit rationing at $\theta^{*}$ & $1-H\left(\theta^{*}\right)$ & $7.7 \%$ & $7.2 \%^{(c)}$ \\
probability of a crisis & $1-H \%$ \\
\hline \hline
\end{tabular}




\section{$5 \quad$ Policy and welfare analysis}

The market for liquidity is inherently inefficient. Normally, markets "create value" by allocating goods from low-value to high-value users. The opposite happens when capital is sold at fire-sales prices in exchange for liquidity. Here goods are allocated from high-value users to low-value users, driven not by "fundamental" valuations but rather by verifiability constraints. These constraints force companies into debt contracts that put them into a straight jacket of tight repayment benchmarks. Default triggers repossession and repossession destroys value. Ultimately, the source of the inefficiency is incompleteness of both contract and market: the access to the technology cannot be traded independently of repayment performance, and the very need for external finance results from the missing insurance market against capital shortages. If this market existed, all investment would have been funded internally, there would be no fire sales, and liquidity would be worthless, privately and socially.

It is thus likely that a welfare-oriented government can prevent some of the value destruction. The main question addressed in this section is what kind of policies are more effective than others; equally important, we provide a preliminary, quantitative assessment of the value created. We analyze three alternative policies: supporting fire-sale prices through liquidity injections, equity injections to the corporate sector, and bailouts that specifically target distressed companies. Both policies involve borrowing so as to fund the liquid inventories that the government needs in order to implement these policies. Since we assume that national debt is paid via lump-sum taxes, the true social cost of the policy is under-accounted for. To address this shortcoming in the analysis, we evaluate policies not just according to the amount of welfare that they generate, but also according to their impact on national debt: the less debt it requires, the more effective the policy is deemed.

\subsection{Liquidity injection}

Suppose that the government can borrow ex ante, build up a position of liquidity, and inject it into the market during times of crisis. Such a welfareoriented government should maximize the expected utility of a typical company. Any losses (in normal times when liquidity is held in vain) or profits (when liquidity is used to buy capital goods cheaply) are returned to the corporate sector via lump-sum taxes or transfers. 
A company may be realized to be either short of capital (SC) or slack (long) in capital (LC), in normal market conditions (N) or in financial crisis (C). In that case, a SC company may be either credit rationed (CR) or not (NR). Table 3 below lists the unconditional expected masses of agents and the payoff for each of these realizations:

\section{Table 3}

Unconditional expected masses and payoffs for various realizations: companies may be capital-short (SC) or capital slacked (LC), in normal (N) market conditions or in crisis (C). SC companies can be either credit rationed (CR) or not (NR).

\begin{tabular}{lll}
\hline \hline Realization & \multicolumn{1}{c}{ Expected mass } & \multicolumn{1}{c}{ Payoff } \\
\hline $\mathrm{N}, \mathrm{LC}$ & $\int_{0}^{\theta^{*}}(1-\theta) h(\theta) d \theta$ & $w^{n}+(2 y-1)$ \\
$\mathrm{N}, \mathrm{SC}$ & $\int_{0}^{\theta^{*}} \theta h(\theta) d \theta$ & $\underline{w}+(2 y-1)-(1-\pi) b(\delta)(2 y-\delta)$ \\
$\mathrm{C}, \mathrm{LC}$ & $\int_{\theta^{*}}^{\bar{\theta}}(1-\theta) h(\theta) d \theta$ & $w^{n} \frac{\delta}{\underline{q}}+\left(2 y-\frac{\delta}{q}\right)$ \\
$\mathrm{C}, \mathrm{SC}, \mathrm{NR}$ & $\int_{\theta^{*}}^{\bar{\theta}} \theta \mu(\theta) h(\theta) d \theta$ & $\underline{w} \frac{\delta}{\underline{q}}+\left(2 y-\frac{\delta}{\underline{q}}\right)-(1-\pi)(2 y-\underline{q})$ \\
$\mathrm{C}, \mathrm{SC}, \mathrm{CR}$ & $\int_{\theta^{*}}^{\bar{\theta}} \theta[1-\mu(\theta)] h(\theta) d \theta$ & $\underline{w} \underline{\underline{q}}$ \\
\hline \hline
\end{tabular}

Using the assumption that $W=1$ we cancel out the redistributive effect of the shock, $\theta$. Hence, the social-welfare function includes the expected level of wealth (plus interest), corporate profits (net of interest charges), with liquidations accounted for in market prices. From that we subtract the government's expected trading losses, or "profits" - net of funding costs. We treat the government as a welfare-oriented speculator; hence, the government incurs trading losses in normal times and profits during crisis when it can buy capital goods at discount prices. We also assume that the government funds its liquid position at the same rate, $\rho_{0}$, as the profit-oriented speculators. Unlike the profit-oriented speculators, it distributes all its profits back to the "population" (of companies) and funds its losses by taxation, all of a lump-sum nature:

$$
\begin{aligned}
S W= & \int_{0}^{\theta^{*}}[1+(2 y-1)-\theta(1-\pi) b(\delta)(2 y-\delta)] h(\theta) d \theta \\
& +\int_{\theta^{*}}^{\bar{\theta}}\left\{\frac{\delta}{\underline{q}}+[1-\theta(1-\mu)]\left(2 y-\frac{\delta}{q}\right)-\theta \mu(1-\pi)(2 y-\underline{q})\right\} h(\theta) d \theta \\
& -\left[H\left(\rho_{0}-1\right)+(1-H)\left(\rho_{0}-\frac{\delta}{\underline{q}}\right)\right] F .
\end{aligned}
$$


Unfortunately, the social-welfare function lacks the usual regularity properties and is thus difficult to analyze. The following proposition reflects this difficulty.

Proposition 4 i) For any probability density function $h$, the social-welfare function is locally increasing in liquidity $F$ at the competitive-equilibrium point. ii) For any density function $h$, there exist a $\rho_{0}>1$ sufficiently low so that the social-welfare function is increasing monotonically over $[0, \bar{\theta}]$ and the optimal liquidity-injection policy involves a zero-probability of crisis. iii) When $\theta$ is uniformly distributed, i.e. $h \equiv 1 / \bar{\theta}$, the policy-maker's problem always has a corner solution with a zero probability of a crisis.

Proof. Due to risk neutrality the objective function can be reduced to expected GDP, net of interest payments on liquidity. Indeed, using equation (11) we derive

$$
\theta \mu(\theta)(1-\pi)(\underline{q}-\delta)=\left(1-\frac{\delta}{\underline{q}}\right) F+\left(1-\frac{\delta}{\underline{q}}\right)[1-\mu(\theta)] \theta,
$$

and simplify the objective function to

$$
\begin{aligned}
& S W=\int_{0}^{\theta^{*}}[2 y-\theta(1-\pi) b(\delta)(2 y-\delta)] h(\theta) d \theta \\
& +\int_{\theta^{*}}^{\bar{\theta}}[2 y-\theta(1-\mu) 2 y+\theta(1-\mu)-\theta \mu(1-\pi)(2 y-\delta)] h(\theta) d \theta \\
& -\left(\rho_{0}-1\right) F .
\end{aligned}
$$

Taking a derivative with respect to $F$ and denoting $\mu^{*} \equiv \mu\left(\theta^{*}\right)$ we get

$$
\begin{aligned}
& \frac{d}{d F} S W=\left[2 y-\theta^{*}(1-\pi) b(\delta)(2 y-\delta)\right] h\left(\theta^{*}\right) \frac{d \theta^{*}}{d F} \\
& -\left[2 y-\theta^{*}\left(1-\mu^{*}\right) 2 y+\theta^{*}\left(1-\mu^{*}\right)-\theta^{*} \mu^{*}(1-\pi)(2 y-\delta)\right] h\left(\theta^{*}\right) \frac{d \theta^{*}}{d F} \\
& +[(2 y-1)-(1-\pi)(2 y-\delta)]\left[1-H\left(\theta^{*}\right)\right] \frac{\partial}{\partial F} \theta^{*} \mu^{*} \\
& -\left(\rho_{0}-1\right)
\end{aligned}
$$

which can be simplified to

$$
\begin{aligned}
& \frac{d}{d F} S W=\left[A_{b} \theta^{*}-A \theta^{*} \mu^{*}\right] h\left(\theta^{*}\right) \frac{d \theta^{*}}{d F} \\
& +A\left[1-H\left(\theta^{*}\right)\right] \frac{\partial\left(\theta^{*} \mu^{*}\right)}{\partial F} \\
& -\left(\rho_{0}-1\right),
\end{aligned}
$$


where

$$
\begin{aligned}
A & =(2 y-1)-(1-\pi)(2 y-\delta), \\
A_{b} & =(2 y-1)-b(\delta)(1-\pi)(2 y-\delta), \\
\frac{d \theta^{*}}{d F} & =\frac{1}{\delta(1-\pi) b(\delta)}, \\
\frac{\partial\left(\theta^{*} \mu^{*}\right)}{\partial F} & =\frac{1}{1+\underline{q}(1-\pi)} .
\end{aligned}
$$

i) Since $A_{b}>A \mu^{*}$ and $\frac{d \theta^{*}}{d F}>0$ we focus on the second and third lines of equation (15). Using condition (13), which determines $F$ in a competitiveequilibrium as

$$
\left[1-H\left(\theta^{*}\right)\right]\left(\frac{\delta}{\underline{q}}-1\right)=\left(\rho_{0}-1\right)
$$

we derive

$$
\begin{aligned}
& A \frac{1-H\left(\theta^{*}\right)}{1+\underline{q}(1-\pi)}-\left(\rho_{0}-1\right) \\
= & \frac{1-H\left(\theta^{*}\right)}{1+\underline{q}(1-\pi)}\left[\left(2 y-\frac{\delta}{\underline{q}}\right)-(1-\pi)(2 y-\underline{q})\right]>0 .
\end{aligned}
$$

ii) We check, first, that $A>0$ by combining

$$
\begin{aligned}
\left(2 y-\frac{\delta}{q}\right)-(1-\pi)(2 y-\underline{q}) & >0 \\
-(1-\pi)(\underline{q}-\delta) & >0 \\
\frac{\delta}{q}-1 & >0 .
\end{aligned}
$$

Since $A_{b}>A$ the first line of equation (15) is positive for any $\mu \in[0,1]$; the whole expression is thus positive for a sufficiently low $\rho_{0}$.

iii) We show, first, that the social-welfare function is convex

$$
\begin{aligned}
\frac{d^{2}}{d F} S W & =\frac{1}{\bar{\theta}} \frac{d \theta^{*}}{d F}\left[A_{b} \frac{d \theta^{*}}{d F}-2 A \frac{d\left(\theta^{*} \mu^{*}\right)}{d F}\right] \\
& =\frac{1}{\bar{\theta}}\left(\frac{d \theta^{*}}{d F}\right)^{2} \frac{d\left(\theta^{*} \mu^{*}\right)}{d F}\left\{\left[A_{b}-A \delta(1-\pi) b(\delta)\right]+(1-\pi)\left[A_{b} \underline{q}-A \delta b(\delta)\right]\right\}>0
\end{aligned}
$$


as $\underline{q}>\delta b(\delta)$, implied by the downward sloping demand for liquidity (Figure $2)$. It is now easy to verify that equation (15) is increasing in the corner, i.e. at the $\theta^{*}=\bar{\theta}$ point.

In the analysis above, $F$ is the aggregate amount of liquidity. Since the government borrows at the opportunity cost of the speculators, and since the speculators make zero expected profit on trade, the division of $F$ between private and public supply makes no difference for the welfare accounting. Since, however, we search for policies that minimize national debt, that distribution is important. The following lemma makes it clear that in a liquidity-injection policy $F$ should be considered as wholly public.

Lemma 3 (Crowding out) As long as speculators participate in the market, public liquidity crowds out private liquidity one-for-one, with no effect on its aggregate supply. Hence, if the government wants to increase the supply of liquidity beyond the competitive level, it will have to supply the entire market, not just the increment above the competitive level.

Proof. As long as speculators participate in the market, the aggregate supply of liquidity - private plus public - is determined via conditions (12) and (13), independently of the composition.

Hence, in order to have any effect, a liquidity-injection policy will have to "nationalize" the market first.

\subsection{Equity injection}

Needless to say, the government faces the same verifiability constraints as the private sector does. Since a shortage of capital is a non-verifiable event, it makes sense to analyze a policy of non-discriminating equity injection to all companies - a bailout (perhaps partial) of the entire corporate sector. We postpone to the next sub-section the analysis of the question whether, and under what informational assumptions, the government can do better by discriminating between distressed and non-distressed companies.

Suppose that the government borrows an amount $E$ and distributes it equally across all the companies in the economy. Having their resources increased to $\underline{w}+E$ will have two effects on capital-short companies. First, being able to fund a greater fraction of the investment internally, during normal times the entrepreneur needs to pledge less as collateral:

$$
\frac{d b(\delta)}{d E} \equiv-\frac{1}{\delta(1-\lambda \pi)+\lambda \pi y}<0 .
$$


During financial crisis the equilibrium $b$ will still be equal to one, but being better capitalized, distressed companies bear lower prices before they hit credit rationing

$$
\frac{d \underline{q}}{d E}=-\frac{\delta}{\sqrt{(\lambda \pi y)^{2}+4(1-\lambda \pi) \delta(1-\underline{w})}}<0 .
$$

An important observation is that the supply of liquidity is:

$$
F+(1-\theta)\left(w^{n}+E-1\right)+\theta(1-\mu)(\underline{w}+E),
$$

where $F$ still denotes the private supply of liquidity (perhaps zero). Hence, all the extra equity that is injected into capital-slack or capital-short companies will find its way into the liquidity market. By the same logic, the demand for liquidity is:

$$
\mu \theta(1-\underline{w}-E)+\theta \mu(1-\pi) \beta q .
$$

Hence, the equity that is injected into capital-short companies will directly decrease their demand for external funding. We can thus calculate:

$$
\begin{aligned}
\theta^{*} & =\frac{F+E}{\delta(1-\pi) b(\delta)}, \\
\mu & =\frac{F+E+\theta}{\theta[1+\underline{q}(1-\pi)]},
\end{aligned}
$$

where

$$
b(\delta)=\frac{1-\underline{w}-E}{\delta(1-\lambda \pi)+\lambda \pi y} .
$$

A crucial observation is immediately apparent: equity injections have the same direct effect on the market as liquidity injections but they also relax financial constraints. Going over the same steps as in the previous subsection, we can see that the social-welfare function is almost identical to equation (14)

$$
\begin{aligned}
& S W=\int_{0}^{\theta^{*}}[2 y-\theta(1-\pi) b(\delta)(2 y-\delta)] h(\theta) d \theta \\
& +\int_{\theta^{*}}^{\bar{\theta}}[2 y-\theta(1-\mu) 2 y+\theta(1-\mu)-\theta \mu(1-\pi)(2 y-\delta)] h(\theta) d \theta \\
& -\left(\rho_{0}-1\right)(F+E) .
\end{aligned}
$$


Proposition 5 Under the conditions established in Proposition 4, an equity injection always dominates a liquidity injection. That includes the case where private speculators are active, and the one-to-one crowding-out result is no longer valid for an equity injection.

Proof. Differentiating (17) with respect to $E$ we get:

$$
\begin{aligned}
& \frac{d}{d E} S W=\left[2 y-\theta^{*}(1-\pi) b(\delta)(2 y-\delta)\right] h\left(\theta^{*}\right) \frac{d \theta^{*}}{d E} \\
& -\frac{d b(\delta)}{d E}(1-\pi)(2 y-\delta) \int_{0}^{\theta^{*}} \theta h(\theta) d \theta \\
& -\left[2 y-\theta^{*}\left(1-\mu^{*}\right)(2 y-1)-\theta^{*} \mu^{*}(1-\pi)(2 y-\delta)\right] h\left(\theta^{*}\right) \frac{d \theta^{*}}{d E} \\
& +[(2 y-1)-(1-\pi)(2 y-\delta)]\left[1-H\left(\theta^{*}\right)\right]\left[\frac{d}{d E} \frac{F(E)+E}{1+\underline{q}(1-\pi)}\right] \\
& -\left(\rho_{0}-1\right),
\end{aligned}
$$

We now need to make a distinction between two cases: where the private speculators are active and where they are not. In the former case,

$$
\begin{aligned}
\frac{d \theta^{*}}{d E} & =-\frac{\left[1-H\left(\theta^{*}\right)\right] \frac{\delta}{q^{2}} \frac{d q}{d E}}{h\left(\theta^{*}\right)\left(\frac{\delta}{q}-1\right)}>0, \\
\frac{d}{d E} \frac{F(E)+E}{1+\underline{q}(1-\pi)} & =\frac{\delta(1-\pi) b(\delta) \frac{d \theta^{*}}{d E}-(F+E) \frac{d \underline{\underline{q}}}{d E}}{[1+\underline{q}(1-\pi)]^{2}} .
\end{aligned}
$$

The notation $F(E)$ is to emphasize crowding out of $F$ by $E$, albeit a partial one. In the later case,

$$
\begin{aligned}
\frac{d \theta^{*}}{d E} & =\frac{1}{\delta(1-\pi) b(\delta)}\left[1-\frac{E}{b(\delta)} \cdot \frac{d b(\delta)}{d E}\right], \\
\frac{d}{d E} \frac{E}{1+\underline{q}(1-\pi)} & =\frac{1}{1+\underline{q}(1-\pi)}\left[1-\frac{(1-\pi)}{1+\underline{q}(1-\pi)} \frac{d \underline{q}}{d E}\right] .
\end{aligned}
$$

Both ways, under the conditions established in Proposition 4, by comparing the derivative above to equation (15) one can establish that the effect of equity injection is greater than the effect of liquidity injection. 
It is worth mentioning that an equity injection can generate welfare even when the probability of a crisis is zero, as it keeps on decreasing the dependence of companies on external finance and the loss of value associated with it. Under the assumption of a lump-sum non-distortionary tax, an equity injection is the optimal policy. Since the assumption is not realistic and since, in reality, the deadweight loss of national debt is substantial, we analyze in the next sub-section a more cost-effective policy.

\subsubsection{Bailouts}

Conventionally, a "bailout" means a government program that buys the liquidation rights of distressed debtors from their respective creditors and writes them off. More graphically, one may visualize a transaction where the government buys the repossessed capital goods from the creditor and gives them back to the distressed debtor - sufficiently fast so that no value is destroyed. We shall assume that the transaction is done at market prices, and that the creditor cannot bargain with the government any higher price.

As described above, even a non-distressed debtor would enroll in a bailout program, cancel as much debt as possible and then negotiate with the creditor a repayment of the rest of the debt (in return for the liquidation rights). To prevent that from happening, the program will have to include some additional terms that would allow distressed debtors to signal their type.

Let

$$
\gamma \equiv \frac{\text { units bailed out }}{\text { units actually liquidated }}
$$

Like the bailout price, we assume that the government commits to a certain $\gamma$ (after the realization of $\theta$ ), which neither the debtor nor the creditor can re-negotiate. Notice that we do make the strong assumption here that "actual liquidation" is an observable action. Moreover, that it perfectly signals the irreversible loss of entrepreneurial rent, proportional to the scale of the action so that the debtor and the creditor cannot collude to fake a liquidation or undo it once it has been taken. To some extent, the strength of this assumption justifies the analysis of the previous sub-section.

In case of repossession the payoffs to the debtor and to the creditor are $\left(1-\beta^{c}\right) y+\gamma \beta^{c} y$ and $\beta^{c} q$, respectively, where $\beta^{c}$ is the contracted collateral, the basis on which the bailout is calculated. As such, there is no reason why $\beta^{c}$ should not exceed one. It is thus more economically meaningful to express 
the problem in terms of the effective collateral, $\beta=(1-\gamma) \beta^{c}$. Defining

$$
\sigma=\frac{\gamma}{1-\gamma}
$$

we can then write

$$
\beta^{c} q=(1+\sigma) \beta q
$$

and interpret $\sigma$ as the relative subsidy paid to creditors on top of the liquidation value $\beta q$. Written in this form, the feasibility constraint of the problem would remain $\beta \leq 1$, as before.

Consider debt renegotiation, when the debtor does not suffer from a liquidity shock, i.e., his date 2 cash flow is $y$. Like before, the debtor and creditor are each granted the opportunity to make a take-it or leave-it offer $R^{D}$ and $R^{C}$ to the other party, with probabilities $(1-\lambda)$ and $\lambda$, respectively. If the debtor wants his offer to be accepted by the creditor, he will have to set it at no less than $R^{D}=(1+\sigma) \beta q$, leaving him with $y-R^{D}$. Clearly, the higher the subsidy, the higher the payment that the creditor can extract from the debtor. If the debtor's offer is not accepted by the creditor, the former receives $(1-\beta) y$. Hence, the government needs to keep the level of the subsidy down to levels that still leave the debtor with an incentive to complete the renegotiations successfully, rather than opt for default. Comparing the two payoffs, it is easy to see that an incentive-compatible bailout policy has to satisfy the following constraint:

$$
\sigma \leq \frac{y-q}{q}
$$

The same constraint applies to $R^{C}$. Intuitively, the constraint implies that the government should keep the after-subsidy fire-sale prices below the fundamental value.

We can now complete the specification of the contract problem in an environment where the government has already announced a policy that satisfies the policy constraint (18). The optimal contract $(R, \beta)$ can be calculated, like before, from the debtor's incentive compatibility constraint on the amount of debt repayment $R$ and creditor's participation constraint. These are given by

$$
\begin{aligned}
R & \leq \beta[(1-\lambda)(1+\sigma) q+\lambda y] \\
\pi R+(1-\pi)(1+\sigma) \beta q & =(1-\underline{w}) \rho_{1}
\end{aligned}
$$


respectively, and the solution to the contract problem is

$$
b=\frac{(1-\underline{w}) \rho_{1}}{q(1+\sigma)(1-\lambda \pi)+\lambda \pi y} .
$$

Clearly, at a given fire-sale price, collateral requirements are decreasing in the subsidy. Notice that once the subsidy hits the policy constraint (18), the denominator in equation (20) reduces to $y$.

Consider, first, an equilibrium with a slack of liquidity $\left(\rho_{1}=1\right)$. In that case the subsidy can go all the way up to the limit defined by the policy constraint (18) which yields $b=(1-\underline{w}) / y<1$. Next, consider the case of a liquidity short equilibrium. Could the subsidy be increased to the point where it hits the (18) constraint? Using (20) we can calculate the equilibrium firesale price that would result, i.e., $q$ that sets $b=1$. This allows us to calculate $\rho_{1}=y /(1-\underline{w})$, which under the parametric assumptions defined in Table 1 would violate assumption (A2). Namely, low fire-sale prices would push the risk free rate of return to a level that would strip companies of any incentive to operate their projects; the government would have to set the subsidy at a lower rate. Regardless of whether liquidity is slack or in short supply, the fiscal cost of an individual bailout is $\sigma(1-\pi) \beta q$ and the cost of the entire program is $\theta(1-\pi) \sigma \beta q$.

Proposition 6 Consider an economy with a "small" equity injection program, $E$, where $E$ is constant across all $\theta$ 's, implemented alongside a competitive liquidity market where speculators supply an amount $F^{*}>0$, the probability of a crisis is $\left(1-H^{*}\right)$ and equilibrium fire-sale prices are $q \in\left\{\delta, q^{*}\right\}$. $A$ bailout program can achieve the same level of collateral requirement (and thus liquidation) at less than a $\bar{\theta} \rho_{1}$ fraction of the national debt, albeit with a possible increase in the cost of aggregate (public plus private) liquidity.

Proof. An equity-injection equilibrium satisfies a market-clearing condition and collateral requirement

$$
\begin{aligned}
W+F^{*}+E-(1-\theta) & \geq \mu \theta\left[1+(1-\pi) \beta^{I} q\right], \\
\beta^{I} & =\frac{(1-\underline{w}-E) \rho_{1}}{q(1-\lambda \pi)+\lambda \pi y},
\end{aligned}
$$

respectively. Now consider a subsidy (contingent on the realized $\theta$ ) of $\sigma=$ 
$\frac{E \rho_{1}}{(1-\pi) \beta^{I} q} ;$ using $(20)$ one can calculate

$$
\bar{\beta}^{\sigma}=\frac{\left(1-\underline{w}-\frac{1-\lambda \pi}{1-\pi} E\right) \rho_{1}}{q(1-\lambda \pi)+\lambda \pi y}<\beta^{I}
$$

(because $\frac{1-\lambda \pi}{1-\pi}>1$ ). Since $\beta$, as defined in equation (20) is decreasing in $\sigma$, $\bar{\beta}^{\sigma}$ is the upper bound on the subsidy that is required in order to implement the $\beta^{I}$ achieved by the equity-injection for any realization of $\theta$. The cost of this program, in the worst possible case where $\theta=\bar{\theta}$, is bounded by $E \rho_{1} \bar{\theta}$. If the government wishes to implement the duplicating subsidy policy in any state of nature then $E \rho_{1} \bar{\theta}$ is the liquid reserve - and the national debt that it needs to create. In all states of nature other than the worse case, the government would have excess liquidity that it can use in order to generate additional welfare.

Notice that under the subsidy, the term $E$ would vanish from the marketclearing condition, but would be substituted by private liquidity according to the crowding-out argument. The aggregate cost of liquidity to the economy, $[F+\bar{\theta}(1-\pi) \sigma \beta q]\left(\rho_{0}-1\right)$, would thus increase although the cost of the public component would decrease.

The original equity-injection program should be small in the sense that the effect of $E$ can be duplicated by the subsidy without violating the (18), namely $E \leq\left.(y-\delta)(1-\pi) \beta^{I}\right|_{q=\delta}$. Also, the equity-injection problem should be small in the sense that $q(\rho)$ will stay sufficiently high (low) so that $\bar{\theta} \rho_{1} \leq 1$

\subsection{Discussion and numerical example}

The stark difference between equation (13), which determines $F$ in a competitive equilibrium, and the government's first-order condition (15) provides a technical substance to the observation above that the market for liquidity is structurally inefficient. Evidently, the difference between the fundamental value of repossessed capital good and their fire-sale price (namely, the loss of value due to liquidation) does not appear in the former expression but does appear in the later. The difference between the expression captures the basic property of our model: that market prices do not reflect the "true" economic value of the commodities traded in the fire-sale market, not even at the margin. As a result, the marginal effect of the policy instrument on the 
equilibrium allocation (namely $\frac{d H}{d F}=h \frac{d \theta^{*}}{d F}$ ), which would have only a secondorder effect on welfare in a Pareto-efficient equilibrium, has a first-order effect in our calculations. Hence, by ex-post redistribution the government recovers missing insurance markets and improves welfare, with the implication of decreasing the probability of crisis.

It is worth pointing out that this result depends on the government accessing some special technologies that private creditors cannot. Our assumptions imply that the government needs to borrow at $t=0$ in order to build up liquid inventories. In normal times it will make no trading profits so that at $t=3$, when the debt is repaid, interest payments (equal to the government's trading losses) will have to be funded by taxation. The government (in this model $^{18}$ ) faces no incentive constraints while borrowing. Also, and unlike private creditors, the government faces no verifiability constraints while taxing. To some extent, this assumption captures a realistic aspect of public policy: private creditors can extract earning only by creating rights on the property of agents to whom they lend, and only to the extent that they can verify the conditionalities involved. The government has greater powers. It need not verify that the tax falls on agents that have benefitted from its spending. Also, the government can tax income indirectly, through another activity (say, consumption) without having to verify a linkage between the two activities. Clearly, the relaxation of these constraints play a crucial role in allowing the government to redistribute income, recover missing markets and improve welfare.

Although policy in our model has a first-order effect on welfare, our numerical examle traces an only modest quantitative effect: a liquidity-injection policy that brings the probability of crisis down to zero would increase welfare by only $0.3 \%$ relative to the competitive equilibrium; see Table 4 . This, surprisingly-small number might seem like an artifact of the model. We believe that this is not the case: the loss of welfare due to financial crisis is, roughly, the loss of output in crisis, times the probability of crisis. Using the actual Reinhart-Rogoff data (a probability of $7.2 \%$ times a GDP decline of $8.8 \%$, see Table 2) will leave us with a simmilar order of magnitude. The annualized debt to GNP figure would be $5.2 \%$ (divide the figure in Table 2 by $2 y / 5)$ not insignificant although probably low in terms of recent experience. A possible explanation is that our model does not fully-capture the

\footnotetext{
${ }^{18}$ In a different paper, the authors analyze the limited capacity of sovereign borrowing. Redistributive shocks play an important role there; see Guembel and Sussman (2009).
} 
leverage of real corporate funding by the financial system. Obviously, the uniform-distribution assumption plays an important role here.

Table 4 also shows the dominance of equity injections over liquidity injections: to bring the probbaility of crisis down to zero it takes an equity injection (and thus national debt as a percentage of full-capacity capital. i.e. one unit) of only $2.4 \%$, with a welfare gain of $0.4 \%$ (compared with $2.6 \%$ and $0.3 \%$ under liquidity injection, respectively). This is because a policy of equity injection affects collateral requirements as well as the the amount of liquidity available to absorb fire-sales. Another advantage of equity injection is that it has some effect when operating side-by side with private liquidity provision, though the effect is small due to the crowding-out effect. Nevertheless, an equity onjection of $1 \%$ would decrease the probability of financial crisis down from $7.7 \%$ in the competitive case (see Table 2) to $7.4 \%$. At this level of implemetation, a bailout policy is even more effective: it can implemet the same level of collateral requirement and liquidation, even under the worst case of $\bar{\theta}$ with national debt of only $0.3 \%$ (instead of ) and leave leave the government with some slacks of liquidity in all other realizations of $\theta$. 


\section{Table 4}

A comparison of welfare and national debt (ND) under competitive equilibrium (CE), liquidity injection (LI), equity injection (EI) and bailouts (BO). EI is implemeted at two levels: either bringing the probability of crisis down to zero $(\mathrm{ZC})$, or at $\mathrm{ND}=1 \%$. $\mathrm{BO}$ is implemeted at a level that would achieve the same $\beta$ as the second EI policy (for any realization of $\theta$ ), leaving the government with a slack of liquidity, generically. ND is expressed as a percentage of full-capacity (i.e. no rationing) capital stock, namely one unit. For structural parameters see Table 1.

\begin{tabular}{lcc}
\hline \hline Description & Model & Value \\
\hline Liquidity injection & $W^{L I-Z C} / S W^{C E}-1$ & $0.3 \%$ \\
welfare gain at ZC & $\bar{\theta} \delta(1-\pi) \beta$ & $2.6 \%$ \\
ND under LI-ZC & & \\
Equity Injection & $S W^{E I-Z C} / S W^{C E}-1$ & $0.4 \%$ \\
welfare gain at ZC & $\bar{\theta} \delta(1-\pi) \beta^{E I}$ & $2.4 \%$ \\
ND under EI-ZC & $S W^{E I-1 \% / S W^{C E}-1}$ & $0.06 \%$ \\
welfare gain at 1\% injection & $1-H\left(\theta^{E I-1 \%}\right)$ & $7.4 \%$ \\
ND & & \\
prob. of crisis & & $0.3 \%$ \\
Bailouts equivalent to 1\% EI & $\bar{\theta} \delta(1-\pi) \beta^{B O}$ & to $0.3 \%$ \\
\hline ND & & \\
government's liquidity slack & & \\
\hline \hline
\end{tabular}

\section{Market fragmentation and market liberal- ization}

It is often claimed that the current crisis is a result of structural changes that took place starting in the 1980s. Since then, the Glass-Steagall act has been removed and banks were allowed to expand trading operations; bankregulation was reduced to capital adequacy requirements; many financial instruments were innovated, some of which (say, securitization) having a direct effect on bank lending; barriers to capital flows were all but eliminated. 
In this section we take a heuristic view of the "old system": the economy was compartmentalized into separate "islands" (regions, industries etc.), each of which was required to be largely self sufficient and provide its own liquidity. Hence, the extent to which a liquidity shortage on one island could spread to another was limited. In this section we analyze how effective that system was in diminishing contagion, and at what cost.

Consider now an extension of the model, in which we allow capital markets to be only partially integrated. Suppose that entrepreneurs can be divided into groups $A$ and $B$, maybe corresponding to a geographical region, or sector of an industry. Let the measure of entrepreneurs in each region be one and suppose that the shock to entrepreneurs' endowments, denoted by $\theta_{A}$ and $\theta_{B}$ have the following joint density $h\left(\theta_{A}, \theta_{B}\right)=\frac{1}{\bar{\theta}\left(\theta_{A}+\theta_{B}\right)}$ on $[0, \bar{\theta}] \times[0, \bar{\theta}]$ with $\theta_{A}+\theta_{B} \leq \bar{\theta}$. It follows that $\theta \equiv \theta_{A}+\theta_{B}$ is uniformly distributed on $[0, \bar{\theta}]$.

Like before, we assume that there are speculators who set aside liquid capital $F$ at $t=0$ before the shocks $\theta_{A}$ and $\theta_{B}$ are realized. Assume that this capital is mobile across regions. Speculators can then allocate liquid funds in order to provide capital to entrepreneurs in either region or save it to buy distressed assets later. In addition suppose there may be liquidity, $L_{A}$ and $L_{B}$, also chosen at $t=0$ that is restricted to be deployed in regions $A$ and $B$, respectively. We allow speculators to invest in this more contrained instrument, if they wish to (we show later that this is not optimal). More realistically, this liquidity could stem, for example from speculators who are restricted to invest locally, maybe due to barriers to capital mobility. Alternatively, if one were to interpret regions as banks, one could think of local liquidity as akin to a capital requirement.

Assume everything else in the model remains unchanged. Therefore, the special case, where $L_{A}=L_{B}=0$ degenerates to the model studied above, where capital markets are fully integrated. ${ }^{19}$

\footnotetext{
${ }^{19}$ Except that the economy is now twice the size as before, but since $\rho_{0}$ and the returns to entrepreneurial activity are independent of scale, this change is immaterial.
} 
Using (10), we can define the following variables:

$$
\begin{aligned}
\widehat{\theta}_{A} & =\frac{L_{A}}{\delta(1-\pi) b(\delta)}, \\
\theta_{A}^{*} & =\frac{F+L_{A}}{\delta(1-\pi) b(\delta)}, \\
\theta_{\max } & =\frac{F+L_{A}+L_{B}}{\delta(1-\pi) b(\delta)} .
\end{aligned}
$$

We can think of $\widehat{\theta}_{A}$ as the largest shock in region $A$, such that no credit rationing occurs, when region $A$ relies solely on its local funds $L_{A}$. Similarly, $\theta_{A}^{*}$ denotes the largest shock such that region $A$ is not credit constrained when it uses its local funds and all pooled funds $F$.

It is clear that the pooled funds will always flow to the region with the higher return. Hence, if one region is credit constrained and the other is not, it must be the case that all pooled funds $F$ are allocated to the constrained region. This allows us to characterize the sets for $\theta_{A}$ and $\theta_{B}$ in which credit rationing occurs. ${ }^{20}$ These are depicted in Figure 3.

\section{Figure 3}

The equilibrium level of liquidation prices $q_{A}$ and $q_{B}$ in regions $A$ and $B$, depending on the realizations of $\theta_{A}$ and $\theta_{B}$.

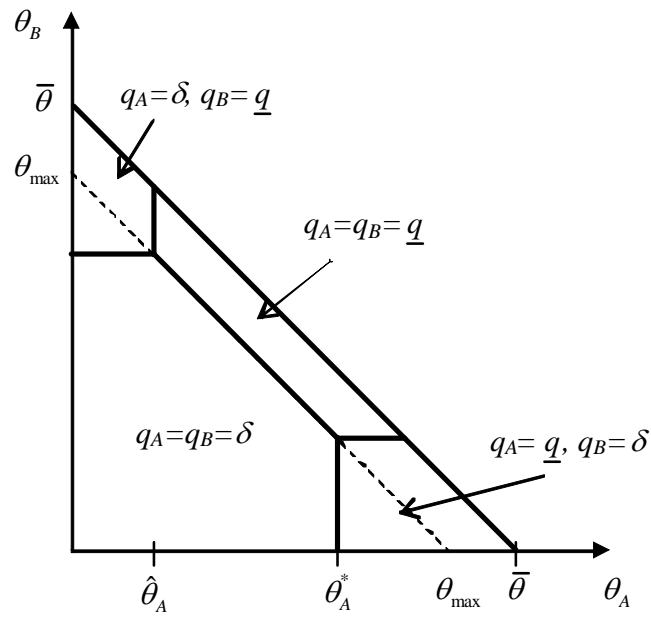

Consider region $A$. If $\theta_{A} \leq \widehat{\theta}_{A}$, then the region's own capital $L_{A}$ is sufficient to avoid credit rationing, no matter what the liquidity demand

\footnotetext{
${ }^{20}$ Like before, we focus only the Pareto dominant equilibrium.
} 
of region $B$. When $\widehat{\theta}_{A}<\theta_{A} \leq \theta_{A}^{*}$ then region $A$ needs to draw on the pooled liquidity in order to avoid credit rationing. To which extent it can do so depends on the shock experienced by region $B$. If $\theta_{B}$ is sufficiently low (namely $\theta_{B} \leq \theta_{\max }-\theta_{A}$ ), both regions will have normal market conditions. However, as $\theta_{B}$ increases, it draws in more of the pooled liquidity, until a point is reached where the pooled liquidity is not sufficient to avoid credit rationing in both regions. This happens when $\theta_{B}>\theta_{\max }-\theta_{A}$. At this point, if one region starts to be credit rationed (say $\theta_{B}$ just tips across the point $\left.\theta_{A}+\theta_{B}=\theta_{\max }\right)$ then the other region will also be rationed. This follows immediately from the downwards sloping demand curves for liquidity.

There is thus contagion across regions: Although conditions in region $A$ are the same, a worsening of the shock in region $B$ spills over and creates credit rationing in region $A$. Contagion makes immediate why local liquidity may be useful: it shields one region from the other region's shock.

On the other hand, if $\theta_{A}>\theta_{A}^{*}$ then region $A$ will always be credit constrained, even though $B$ may not be. Here, region $A$ is using up all of its own liquid capital as well as the speculators' funds. In part of this region credit rationing in region $A$ could be avoided if bank $B$ 's capital could be reallocated to $A$. The cost of constraining some liquidity to be local is thus the fact that it may remain unused in one region, although the other region is in need of it.

An interesting question this discussion raises, is how relaxing regulatory requirements that lead to a lowering of $L_{A}$ and $L_{B}$, would affect the probability of a crisis in one or both regions, and ultimately how (de-)regulation affects overall welfare. We now turn to these questions.

Denote by $\rho_{F}$ and $\rho_{A}$ the realized rate of return on pooled liquidity $F$ and local liquidity $L_{A}$, respectively. Obviously, $\rho_{F}=1$ if there are normal market conditions in both islands and $\rho_{F}=\frac{\delta}{q}$ otherwise. Similarly, $\rho_{A}=1$ if there are normal market conditions in region $A$ and $\rho_{F}=\frac{\delta}{q}$ otherwise. We can calculate the probabilities of high / low returns on local or pooled liquidity by integrating the density function $h\left(\theta_{A}, \theta_{B}\right)$ over the appropriate intervals 
depicted in Figure 3. This yields:

$$
\begin{aligned}
\operatorname{Pr}\left(\rho_{F}=1\right)= & \frac{\theta_{\max }}{\bar{\theta}}\left(\ln \theta_{\max }-\ln \left(\theta_{\max }-\widehat{\theta}_{A}\right)\right)+\frac{\theta_{A}^{*}}{\bar{\theta}}\left(1+\ln \theta_{\max }-\ln \theta_{A}^{*}\right) \\
& -\frac{\widehat{\theta}_{A}}{\bar{\theta}}\left(1+\ln \theta_{\max }-\ln \left(\theta_{\max }-\widehat{\theta}_{A}\right)\right) \\
\operatorname{Pr}\left(\rho_{A}=1\right)= & \frac{1}{\bar{\theta}}\left(\theta_{A}^{*}\left(1+\ln \theta_{\max }-\ln \theta_{A}^{*}\right)+\widehat{\theta}_{A}\left(\ln \bar{\theta}-\ln \theta_{\max }\right)\right) .
\end{aligned}
$$

We first address the question whether unconstrained speculators ever wish to invest in $L_{A}$ or $L_{B}$, instead of $F$. We thus ask what the equilibrium amount of local liquidity is in the absence of regulation.

Lemma 4 In a competitive equilibrium of an unregulated economy, the amount of liquidity supplied locally $\left(L_{A}, L_{B}\right)$ is zero and pooled liquidity is

$$
F=\bar{\theta} \delta(1-\pi) b(\delta) \frac{\frac{\delta}{q}-\rho_{0}}{\frac{\delta}{\underline{q}}-1} .
$$

A crisis occurs with probability $\frac{\rho_{0}-1}{\frac{\delta}{\underline{\delta}}-1}$.

Proof. From the above we can show that $\operatorname{Pr}\left(\rho_{A}=1\right)>\operatorname{Pr}\left(\rho_{F}=1\right)$ can be rewritten as

$$
\frac{L_{A}}{F+L_{B}}\left(\ln \bar{\theta}-\ln \eta\left(F+L_{A}+L_{B}\right)\right)+\frac{L_{A}}{F+L_{B}}>\left(\ln \left(1+\frac{L_{A}}{F+L_{B}}\right)\right),
$$

which is always true for $L_{A}>0$. (Note that this statement is also obvious from the Figure). It follows that the expected return on locally constrained liquidity is strictly lower than on unconstrained liquidity.

$F$ is determined by the condition

$$
\operatorname{Pr}\left(\rho_{F}=1\right)+\frac{\delta}{\underline{q}}\left(1-\operatorname{Pr}\left(\rho_{F}=1\right)\right)=\rho_{0} .
$$

Using the fact that $L_{A}=L_{B}=0$ and substituting into $\operatorname{Pr}\left(\rho_{F}=1\right)$ yields the result. Moreover, $\operatorname{Pr}\left(\rho_{F}>1\right)=\frac{\rho_{0}-1}{\frac{\delta}{\underline{q}}-1}$ follows directly from the equilibrium condition (21). 
The above lemma indicates that in the absence of regulatory constraints, regions will not hold liquid capital that is earmarked for internal use only. This provides a benchmark for comparison with the case where regions are constrained (by regulation or market segmentation) to hold a strictly positive $L_{A}$ and $L_{B}$.

Once we allow for local liquidity, a crisis may take different forms: (i) there is a crisis in region $A$ only, (ii) there is a crisis in region $B$ only, (iii) there is a crisis in both regions. Denote each by $p_{A}, p_{B}$, and $p_{A \curlywedge B}$, respectively. We know that $\rho_{F}>1$ if and only if one of the three events occurs. Hence $\operatorname{Pr}\left(\rho_{F}>1\right)=p_{A}+p_{B}+p_{A \curlywedge B}$.

In order to assess the impact of the constraint, one needs to take into account its direct effect on the incidence of a crisis of one bank, and the extent to which regulation crowds out liquidity supplied by speculators. The following Proposition speaks to that question.

Proposition 7 An increase in $L_{A}$ leads to partial crowding out of $F$ (i.e., $\left.0>\frac{\partial F}{\partial L_{A}}>-1\right)$ up to a point $\bar{L}_{A}$ where $F=0$. For $L_{A}<\bar{L}_{A}$, an increase in $L_{A}$ reduces the probability $p_{A \curlywedge B}$ of a systemic crisis, but it does not affect the probability $p_{A \curlywedge B}+p_{A}+p_{B}$ that at least one region experiences a crisis.

Proof. We know that the competitive allocation of $F$ is determined by the condition $\operatorname{Pr}\left(\rho_{F}=1\right)+\frac{\delta}{q}\left(1-\operatorname{Pr}\left(\rho_{F}=1\right)\right)=\rho_{0}$, if $L_{A}$ and $L_{B}$ low enough so that at $F=0$ we have $\operatorname{Pr}\left(\rho_{F}>1\right)>\frac{\rho_{0}-1}{\frac{\delta}{q}-1}$. It follows that in this case $F$ is such that $p_{A}+p_{B}+p_{A \curlywedge B}=\frac{\rho_{0}-1}{\frac{\delta}{q}-1}$, i.e., a change in $L_{A}$ does not affect the overall probability of a crisis somewhere.

We can calculate

$$
\begin{aligned}
p_{A \curlywedge B}= & \int_{\widehat{\theta}_{A}}^{\theta_{A}^{*}} \int_{\theta_{\max }-\theta_{A}}^{\bar{\theta}-\theta_{A}} \frac{1}{\bar{\theta}\left(\theta_{A}+\theta_{B}\right)} d \theta_{B} d \theta_{A} \\
& +\int_{\theta_{A}^{*}}^{\theta_{A}^{*}+\bar{\theta}-\theta_{\max }} \int_{\theta_{\max }-\theta_{A}^{*}}^{\bar{\theta}-\theta_{A}} \frac{1}{\bar{\theta}\left(\theta_{A}+\theta_{B}\right)} d \theta_{B} d \theta_{A}
\end{aligned}
$$

This can be rewritten as

$$
\begin{aligned}
p_{A \curlywedge B}= & \frac{1}{\bar{\theta}}\left(\theta_{A}^{*}-\widehat{\theta}_{A}\right)\left(\ln \bar{\theta}-\ln \theta_{\max }\right) \\
& +\frac{1}{\bar{\theta}}\left(\bar{\theta}-\theta_{\max }\left(1+\ln \bar{\theta}-\ln \theta_{\max }\right)\right) .
\end{aligned}
$$


It is clear that the first term is decreasing in $L_{A}$. Taking the derivative of the second term with respect to $L_{A}$ yields $-\frac{\ln \bar{\theta}-\ln \theta_{\max }}{\bar{\theta} \delta(1-\pi) b(\delta)}<0$, so $p_{A \curlywedge B}$ is decreasing in $L_{A}$.

When $L_{A}$ is injected, $F$ of the competitive equilbrium adjusts such that $C o C_{F}=0$. Hence, $F$ is given as an implicit function of $L_{A}$. Using the implicit function theorem we can calculate the extent of crowding out as

$$
\frac{d F}{d L_{A}}=-\frac{\frac{F}{F+L_{A}+L_{B}}+\ln \left(\eta\left(F+L_{A}+L_{B}\right)\right)-\ln \left(\eta\left(F+L_{A}\right)\right)}{\frac{F}{F+L_{A}+L_{B}}+2\left(\ln \left(\eta\left(F+L_{A}+L_{B}\right)\right)-\ln \left(\eta\left(F+L_{A}\right)\right)\right)}>-1 .
$$

Although market fragmentation cannot affect the overall probability of a crisis because of crowding out, it dampens contagion: There are now realizations for $\theta_{A}$ such that a crisis does not occur in region $A$ when one would have occurred in the absence of a regulatory requirement on $L_{A}$. Take values $\theta_{A}<\widehat{\theta}_{A}$, where the locally constrained liquidity avoids a crisis in region $A$ for any value of $\theta_{B}$. If markets were fully integrated $\left(L_{A}=L_{B}=0\right)$, a crisis in $A$ would have occurred whenever $\theta_{B}>\frac{F}{\delta(1-\pi) b(\delta)}-\theta_{A}$. This means that some crises will be contained locally, when they would have spilled over to the other region in a fully deregulated market.

The fact that we now have a lower probability of a crisis in both regions, would suggest that total output should increase. This, however, is not entirely clear for the following reason. An increase, say in $L_{A}$ crowds out some $F$. As a result, if there is a crisis that is contained in region $B$, a higher $L_{A}$ reduces the available liquidity in region $B$ increasing the number of capital rationed entrepreneurs there. Thus, although the crisis is contained in region $B$ it is now deeper there.

Of course, market fragmentation has an additional cost. Since the $\operatorname{Pr}\left(\rho_{A}>1\right)<$ $\operatorname{Pr}\left(\rho_{F}>1\right)$, the rate of return on $L_{A}$ is lower than $\rho_{0}$. Hence, there is an opportunity cost of the locally constrained liquidity, which is due to the fact that it is used inefficiently (i.e., not used) when bank $B$ experiences a crisis.

Although a full welfare analysis of this case remains to be completed, it is clear at this stage that deregulation may increase the incidence of a systemic crisis. The advantage of liberalization is that liquidity will be used more efficiently. Although it also increases the amount of liquidity made available by speculators, the relation is not one for one, so that total liquidity falls with deregulation. Since liquidity is a public good, deregulation leads to its underprovision. The conclusion of this observation, however, should not be to stop deregulation, but instead to subsidize the provision of liquidity. 


\section{Conclusions}

This paper provides an analytical framework for the study of liquidity crises. It is couched firmly in a neo-classical framework with contracting frictions. The destablizing effect of the market for liquidity derives from one simple peculiarity: demand and supply are sloping in the same direction. This observation allows us to capture the phenomenon of a crisis, which may occur both as a multiple equilibrium outcome, or as the unique equilibrium, depending on the magnitude of an aggregate shock.

Although many of the ingredients of our model have been used elsewhere, our framework unifies them and allows a simple and realistic characterization of crises. This allows us to generate a simple and observable measure of welfare and thus lends credibility to our policy analysis. In it, we find that the welfare gains from liquidity injections or bailouts by the government improve welfare, but only by a small amount. This is surprising, given the dramatic price effects of a crisis.

An interesting avenue for further research would be to link the current analysis more closely to macroeconomic questions of monetary and fiscal policy. Some of that literature uses concepts that are closely related to our, more micro founded analysis, for example cash-in-advance constraints or a liquidity trap. A full integration of the macro and microeconomic research in this fields remains an open topic for research.

\section{Appendix: sensitivity analysis}

To check the robustness of our numerical example, we calculate below the elasticity of the key endogenous variables with respect to the main structural parameters. As key endogenous variables we consider the three variables in Table 2, for which there is actual data, namely those that are used in order to check the model's quantitative fit. These variables are: price-drop in crisis, output-drop in crisis and the probability of a crisis. We describe the results of the exercise in Table A1 below. To remove doubt, the result should be red as follows: a -2.92 elasticity of the probability of crisis with respect to the wealth endowment of capital-short companies means that when the latter increases from 0.6 to 0.606 , the former falls from $7.7 \%$ to $7.5 \%$. Obviously, the calculations are valid for a single point in the parameter space, namely that which is characterized by Table 1 . Since all the main results are based on the model's non-linearity, it is important to check that this point in the 
parameter space is not knife-edged, namely that the sensitivity of the results to the parameters is not explosive. Indeed, the analysis seems to confirm that the model is (locally) stable in that respect: the highest elasticity is just below 3 and many below 1 .

\section{Table A1}

Sensitivity analysis: the elasticity of key endogenous variables with respect to some of the structural parameters: price drop in crisis, output drop in crisis and the probability of crisis.

\begin{tabular}{cccc}
\hline \hline & $\frac{\underline{\bar{\delta}}}{\delta}-1$ & $\left.Y\right|_{q=q} /\left.Y\right|_{q=\delta}-1$ & $1-H\left(\theta^{*}\right)$ \\
\cline { 1 - 1 } parameters & & & \\
$\delta$ & 0.34 & 0.26 & -0.57 \\
$y$ & 0.85 & 0.97 & -1.39 \\
$\pi$ & 0.65 & $-2,65$ & -1.06 \\
$\underline{w}$ & 1.81 & 1.73 & -2.92 \\
\hline \hline
\end{tabular}

\section{References}

[1] Acharya, V., H.S. Shin and T. Yorulmazer, 2008, "Fire Sales, Foreign Entry and Bank Liquidity," unpublished manuscript, Princeton University.

[2] Acharya, V., H.S. Shin and T. Yorulmazer, 2009, "A Theory of SlowMoving Capital and Contagion," unpublished manuscript, Princeton University.

[3] Allen, F. and D. Gale, 1998, "Optimal Financial Crisis," Journal of Finance, 53, 1245-1284.

[4] Bagehot, W., 1873, Lombard Street: A Description of the Money Market, London: Henry S. King and Co.

[5] Bernanke, B. and M. Gertler, 1989, "Agency Costs, Net Worth and Business Fluctuations," American Economic Review, 79(1), 14-31.

[6] Bolton, P., T. Santos and J. Scheinkman, 2008, "Inside and Outside Liquidity", unpublished manuscript, Columbia University. 
[7] Bolton, P., T. Santos, and J. Scheinkman, 2009, "Market and Public Liquidity," American Economic Review Papers and Proceedings forthcoming. unpublished manuscript, Columbia University.

[8] Brown, D., 2000, "Liquidity and Liquidation: Evidence from Real Estate Investment Trusts," Journal of Finance, LV, 469-485.

[9] Brunnermeier, M. and L. Pedersen, 2008, "Market Liquidity and Funding Liquidity," forthcoming Review of Financial Studies.

[10] Caballero, D. and A. Krishnamurthy, 2001, "International and Domestic Collateral Constraints in a Model of Emerging Market Crisis," Journal of Monetary Economics, 48, 513-548.

[11] Caballero, D. and A. Krishnamurthy, 2003, "Excessive Dollar Debt: Financial Development and Underinsurance," Journal of Finance, 58, 867893.

[12] Caballero, R. and A. Krishnamurthy, 2004, "Smoothing Sudden Stops," Journal of Economic Theory, 119, 104-127.

[13] Diamond, D. and P. Dybvig, 1983, "Bank Runs, Deposit Insurance and Liquidity," Journal of Political Economy, 91, 401-419.

[14] Dow, J., 2004, "Is Liquidity Self-fulfilling?" Journal of Business, 77, 895-908.

[15] Fisher, I., 1933, "The Debt-Deflation Theory of Great Depressions," Econometrica, 1, 337-357.

[16] Fostel, A. and J. Geanakoplos, 2008(a), "Collateral Restrictions and Liquidity Under-Suplly: A Simple Model," Economic Theory, 35, 441467.

[17] Fostel, A. and J. Geanakoplos, 2008(b), "Leverage Cycles and the Anxious Economy," American Economic Review, 98, 1211-1244.

[18] Franks, J. and O. Sussman. 2005, "Financial Distress and Bank Restructuring of Small to Medium Size UK Companies," Review of Finance, 9, 65-96. 
[19] Gorton, G., and L. Huang, 2004, "Liquidity, Efficiency, and Bank Bailouts," American Economic Review, 94(3), 455-483.

[20] Gromb, D. and D. Vayanos, 2002, "Equilibrium and Welfare in Markets with Financially Constrained Arbitrageurs," Journal of Financial Economics, 66, 361-407.

[21] Guembel A., and O. Sussman, 2009, "Sovereign Debt without Default Penalties," Review of Economic Studies, 76(4), pp. 1297-1320.

[22] Hart, O. and J. Moore, 1998, "Default and Renegotiation: A Dynamic Model of Debt," Quarterly Journal of Economics, 113, 1-41.

[23] Holmstrom B. and J. Tirole, 1997, "Financial Intermediation, Loanable Funds, and the Real Sector," Quarterly Journal of Economics, 112, 663692.

[24] Holmstrom, B. and J. Tirole, 1998, "Private and Public Supply of Liquidity," Journal of Political Economy, 106, 1-40.

[25] Holmstrom, B. and J. Tirole, 2008, "Inside and Outside Liquidity" Wicksell Lectures, http://idei.fr/doc/by/tirole/wicksell_lectures.pdf.

[26] Kiff J. V. Klyuev, 2009, "Foreclosure Mitigation Efforts in the United States Approaches and Challenges," IMF, SPN/09/02.

[27] Kiyotaki, N. and J.H. Moore, 1997, "Credit Cycles," Journal of Political Economy, 105, 211-248.

[28] Mayer, C, 1988 "New Issues in Corporate Finance," European Economic Review, 32, 1167-1189.

[29] McKay, C., 1841, Extraordinary Popular Delusions $\&$ the Madness of Crowds, Modern edition: New York: L. C. Page \& Co., (1958).

[30] Lorenzoni, G., 2008, "Inefficient Credit Booms," Review of Economics Studies, 75, 809-833.

[31] Morris, S. and H.S. Shin, 2004, "Liquidity Black Holes," Review of Finance, 8, 1-18. 
[32] Pulvino, T., 1998, "Do Asset Fire Sales Exist?" Journal of Finance, 53, 939-978.

[33] Rajan, R. J. and L. Zingales 1995, "What Do We Know About Capital Structure? Some Evidence from International Data" Journal of Finance, $50,1421-1460$.

[34] Rampini, A. and S. Viswanathan, 2008, "Collateral, Financial Intermediation and the Distribution of Debt Capacity," unpublished manuscript, Duke University.

[35] Reinhart, C. M. and R. S. Rogoff, 2008. "Banking Crises: An Equal Opportunity Menace", NBER working paper No. 14587.

[36] Reinhart, C. M. and R. S. Rogoff, 2009. "The Aftermath of Financial Crisis", American Economic Review, 99, 466-72.

[37] Shiller, R., 2000, Irrational Exuberance, New Jersey: Princeton University Press.

[38] Suarez, J. and O. Sussman, 1997, "Endogenous Cycles in a Stiglitz-Weiss Economy," Journal of Economic Theory, 76, 47-71.

[39] Suarez, J. and O. Sussman, 2007, "Financial Distress, Bankruptcy Law and the Business Cycle," Annals of Finance, 3, 5-35. 